\title{
COVID-19 and Rheumatoid Arthritis Crosstalk: Emerging association, therapeutic options, and challenges
}

Saikat Dewanjee ${ }^{1 \#, ~ R a m e s h ~ K a n d i m a l l a ~}{ }^{2,3 \#}$, Rajkumar Singh Kalra ${ }^{4, \dagger}$, Chandrasekhar valupadas $^{5}$, 6 , Jayalakshmi Vallamkondu ${ }^{7}$, Viswakalyan Kolli, Arubala Reddy ${ }^{9}$, P. Hemachandra Reddy ${ }^{10-14^{*}}$

${ }^{1}$ Advanced Pharmacognosy Research Laboratory, Department of Pharmaceutical Technology, Jadavpur University, Kolkata 700032, India

${ }^{2}$ Applied Biology, CSIR-Indian Institute of Technology, Uppal Road, Tarnaka, Hyderabad 50000, Telangana, India

${ }^{3}$ Department of Biochemistry, Kakatiya Medical College, Warangal 506007, Telangana, India

${ }^{4}$ AIST-INDIA DAILAB, National Institute of Advanced Industrial Science \& Technology (AIST), Higashi 1-1-1, Tsukuba 305 8565, Japan

${ }^{5}$ Professor, Internal Medicine \& Medical Superintendent, MGM Hospital, Warangal, India

${ }^{6}$ In charge Medical Superintendent, KMC Superspeciality Hospital, Warangal, India

${ }^{7}$ National Institute of Technology, Warangal 506004, Telangana, India

${ }^{8}$ Professor, Department of Biochemistry, GITAM Institute of Medical Sciences and Research, Visakhapatnam, India

${ }^{9}$ Nutritional Sciences, Texas Tech University, Lubbock, Texas, USA

${ }^{10}$ Texas Tech University Health Sciences Center, Lubbock, TX, USA

${ }^{11}$ Neuroscience \& Pharmacology, Texas Tech University Health Sciences Center, Lubbock, TX, USA

${ }^{12}$ Departments of Neurology, School of Medicine, Texas Tech University Health Sciences Center, Lubbock, TX, USA

${ }^{13}$ Public Health Department of Graduate School of Biomedical Sciences, Texas Tech University Health Sciences Center, Lubbock, TX, USA

${ }^{14}$ Department of Speech, Language and Hearing Sciences, School Health Professions, Texas Tech University Health Sciences Center, Lubbock, TX, USA

†Present address: Immune Signal Unit, Okinawa Institute of Science and Technology Graduate University, 1919-1 Tancha, Onna-son, Okinawa, 904-0495, Japan.

Email: rajkumar-singh@oist.jp

\#Equal Contribution; Equal First Author

*Corresponding authors: hemachandra.reddy@ttuhsc.edu 


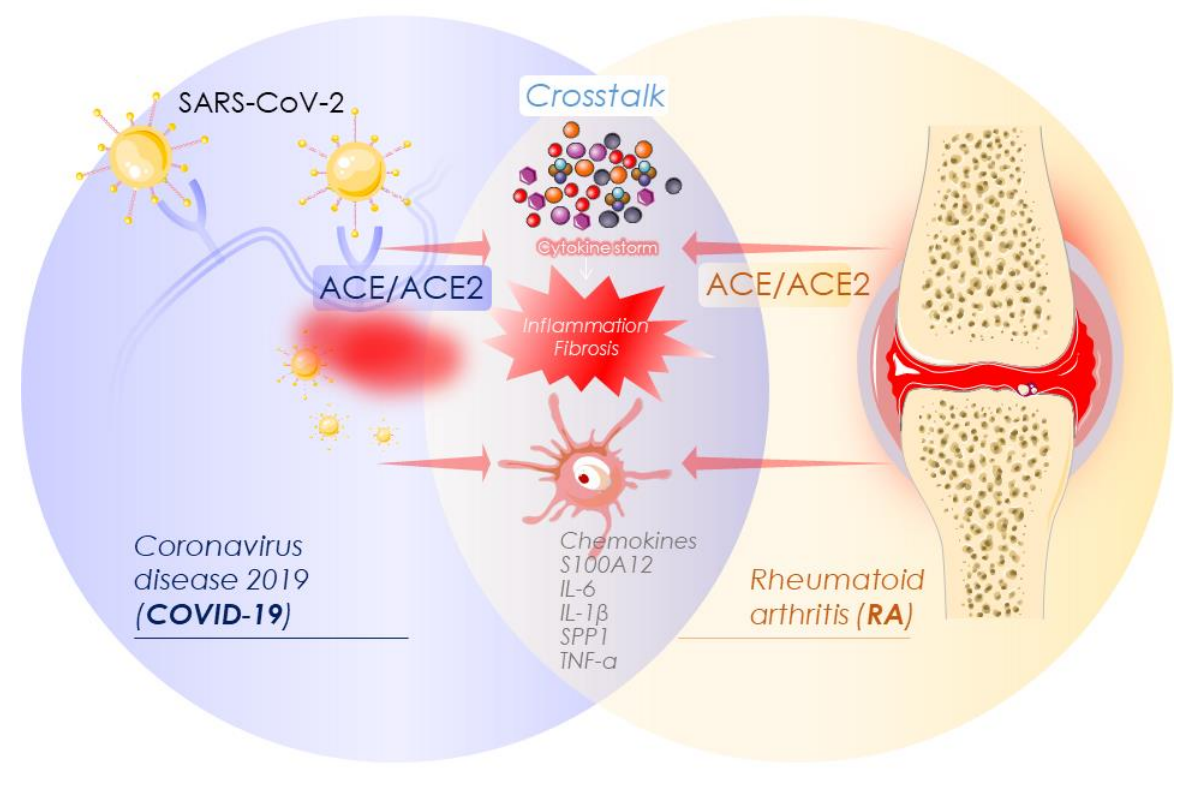

\section{GRAPHICAL ABSTRACT}

\section{Highlights}

- COVID-19 pro-inflammatory response clinically resembles RA disease features

- COVID-19 and RA clinical crosstalk involves components of adaptive immune response

- ACE/ACE2 and macrophage-mediated pathways share mechanistic overlapping in both cases

- Disease severity, age, and comorbidities are critical factors in drug selection. 


\section{ABSTRACT}

Excessive immune activation and cytokine release in alveoli/lung structures is a prominent sign of coronavirus disease 2019 (COVID-19) pathology caused by infectious severe acute respiratory syndrome coronavirus 2 (SARS-CoV-2). The progressive sign of pro-inflammatory cytokines elicited in COVID-19 clinically resembles hyper immunereactive features often seen in rheumatoid arthritis (RA), an autoimmune disorder. Recent clinical data from the ongoing COVID-19 pandemic conferred the severity and risk of COVID-19 to RA patients. Amid the evidence of musculoskeletal manifestations involving immune-inflammation-dependent mechanisms and cases of arthralgia and/or myalgia in COVID-19, crosstalk between COVID-19 and RA is debated. The present review sheds light on the overlapping COVID-19 and RA clinical features, aspects of SARS-CoV-2 infection in RA development, and associated risks. It also confers whether RA can worsen COVID-19 outcomes based on available clinical readouts. To gain mechanistic insights into the overlapping immune-inflammatory features in SARS-CoV-2 infection and RA, we reviewed the emerging links of angiotensin-converting enzyme (ACE)-dependent and macrophage-mediated pathways. Moreover, a detailed review of immediate challenges and key recommendations for anti-rheumatic drugs in the COVID-19 setting was presented for better clinical monitoring and management of RA patients. Taken together, present review summarizes available knowledge on the emerging COVID-19 and RA crosstalk and their mechanistic overlaps, challenges, and therapeutic options.

Keywords- ACE; ACE2; anti-rheumatic drugs; COVID-19; cytokine storm; immune response; inflammation; rheumatoid arthritis; SARS-CoV-2; therapeutic options. 


\section{Abbreviations}

ACE: Angiotensin-converting enzyme; ACE2: Angiotensin-converting enzyme 2; ACPA: anti-citrullinated peptide antibody; APC: Antigen presenting cell; bDMARDs: Biological disease-modifying antirheumatic drugs; BMD: bone marrow density; COVID-19: coronavirus disease 2019; csDMARDs: Conventional synthetic disease-modifying antirheumatic drugs; IFN: interferon; IL: Interleukin; NK: Natural killer cells; NSAIDs: Non-steroidal anti-inflammatory drugs; RA: rheumatoid arthritis; SARS-CoV-2: Severe acute respiratory syndrome coronavirus 2; Th: T helper; tsDMARDs: Targeted synthetic disease-modifying anti-rheumatic drugs. 


\section{Introduction}

Severe acute respiratory syndrome coronavirus 2 (SARS-CoV-2) infection that caused coronavirus disease 2019 (COVID-19) usually produces a mild to moderate respiratory disease [1]. However, it occasionally leads to severe alveolar disease resulting in shortening of breath, reduced oxygen saturation in blood, and pulmonary infiltration in the lung that can substantially contribute to pulmonary failure [2]. Age, the severity of infection, and the existence of comorbidity are potential risk factors in COVID-19 patients [1]; [3]. Emerging evidence revealed that SARS-CoV-2 develops a specific type of alveolar disease that is clinically different from other acute respiratory syndromes [2]. Immune hyperactivation and cytokine involvement in alveolar structures have been identified as the key contributors to produce severe lung disease in COVID-19 patients. The patterns of cytokine and immune activation in COVID-19 patients seem to resemble rheumatoid arthritis (RA) case and interestingly these are the major therapeutic targets in both COVID-19 and RA patients [2]. Thus, a possibility of pathological crosstalk is inevitable between COVID-19 and RA.

In general, there is a close association between viral infection and arthritis with a wide spectrum of symptoms ranging from arthralgia to arthritis. Earlier reports revealed that hepatitis $C$ and several alphaviruses frequently develop prolonged arthritis; however, Parovirus B19, hepatitis B, and Rubella viruses frequently cause self-limited arthritis. In contrast, respiratory viruses, such as corona and influenza viruses more frequently develop arthralgia and/or myalgia. Approximately 15 and $44 \%$ of COVID-19 patients present arthralgia and/or myalgia respectively during the infective stage [4]. Emerging evidence hypothesized that SARS-CoV-2 infection can attack musculoskeletal systems through immune-inflammation-dependent mechanism [3] [5]; which may develop inflammatory arthritis during the infective or post-infective stage [4]. However, little is known about the manifestations or worsening of RA by this infection. Since musculoskeletal manifestations phenotypically resemble RA, thus it has been attempted to find out the association between COVID-19 and RA. Special emphasis was given on therapeutic strategy and therapeutic challenges in different case studies. 


\section{COVID-19 and RA association}

Emerging evidence revealed that respiratory viral infections can increase the risk of autoimmune inflammatory arthritis, such as RA [6]. In addition, infections can flare the disease in the patients with inflammatory arthritis [7]. Thus, SARS-CoV-2 infection may potentially contribute to RA development or disease flares. So far little information is available and it is too early to predict the direct association between SARS-CoV-2 infection and RA development [8]. However, considering the existing evidence it can be hypothesized that COVID-19 may play a causative effect in RA development or can worsen the RA complications. The respiratory tract suggested to be the primary site of SARS-CoV-2 infection; however, skeletal muscle, synovium, and cortical bone have been revealed to be the other possible sites of direct SARS-CoV-2 infection [9]. Various anatomical levels of musculoskeletal abnormalities in muscles, bones, and joints were detected in image analysis of COVID-19 patients [10]. Myalgia has been identified as a major clinical presentation of skeletal muscle manifestation in SARS-CoV-2 infection [11]. It can also stand as an important predictive factor for the severity of SARS-CoV-2 infection [12]. Due to the evolving nature of COVID-19, the mechanistic insight of skeletal muscle manifestation is yet to be clearly interpreted. However, muscle fiber atrophy, sporadic and focal muscle fiber necrosis, and immune cell infiltration have been postulated to be the etiological factors involved in the skeletal muscle injury during coronavirus infection [9]. Systemic activation of pro-inflammatory molecules can potentially contribute to muscle fiber proteolysis and decrease protein synthesis [9]. Muscle injury has been regarded as an important contributor to RA-induced morbidity and mortality [13]. Bone and joint manifestation have a broad spectrum in COVID-19 with common viral arthralgia [14]. It has been reported that about $27 \%$ of patients demonstrate joint pain even after recovery from COVID-19 disease [15]. Arthralgia was reported in COVID-19 patients; however, it is more frequently appeared along with myalgia. Arthralgia and reduced bone marrow density (BMD) is also frequent in SARS infection, particularly to the patients undergo glucocorticoid treatment [9]. Glucocorticoids can also increase the risk of osteonecrosis, osteoporosis, and BMD in COVID-19 patients [14]. SARS-CoV-2 infection generally triggers inflammatory 
mediators including C-X-C motif chemokine ligand 10 (CXCL10), interleukin (IL) -17, and tumor necrosis factor-alpha (TNF- $\alpha$ ), which play causative roles in the initiation of osteoclastogenesis and reduction in osteoblast differentiation and proliferation, resulting in a net fall in BMD [9]. In addition, IL-1 $\beta$, IL-6, and TNF- $\alpha$ activation during SARS-CoV2 infection may impart arthralgias or osteoarthritis progression by inducing chondrolysis in an inflammation-dependent mechanism [9].

\subsection{Can SARS-CoV-2 infection trigger RA development?}

In general, viruses can produce arthritis either through direct colonization at the joints or through aberrant immune-inflammation reaction produced during the host response to the infection. Earlier reports mentioned that the respiratory viruses can be associated with RA development [7]. Moreover, the evidence of SARS-CoV-2 infection in rheumatic and autoimmune manifestations is not uncommon [16]. The onset of arthritis after SARS-CoV-2 infection has been postulated earlier [17]. Derksen and coworkers (2021a) reported 3 out of 61 COVID-19 positive patients developed polyarthritis that resembles regular RA after infection [18]; however, they did not find any increase in anticitrullinated peptide antibody (ACPA) seroprevalence. In this, COVID-19-provoked inflammation may be a potential contributor in developing arthritis in a citrullinationindependent pathway. In a recent report, Perrot and colleagues (2021) first mentioned a case of ACPA-positive RA development immediately after SARS-CoV-2 infection that further worsens RA symptoms [19]. In another report, Roongta and co-workers (2021) reported a case of seropositive RA after SARS-CoV-2 infection, which has been mentioned as sixth case of COVID-19-induced seropositive RA manifestation. All 6 patients represent negative serology before infection [20]. However, more data are required to know that whether RA manifestation following SARS-CoV-2 infection is connected or coincidence.

\subsection{Can RA increase the risk of acquiring COVID-19 infection?}

Emerging evidence revealed that patients with immune-mediated inflammatory diseases are more vulnerable to severe SARS-CoV-2 infections than to the general population, which may arise due to their immune dysfunction and as a consequence of 
immunosuppressant therapy [21]. Accumulated data of 7 case-control studies showed that the risk of symptomatic COVID-19 is almost 2 times prevalent in patients with immune-mediated inflammatory diseases than that of general people [22]. In a large worldwide case series of rheumatoid patients, COVID-19 severity and death was significantly high as compared to general population [23]. According to COVID-19 global rheumatology alliance (GRA) global registry, out of 7263 COVID-19 cases, 2956 patients were documented to have RA, which is accounting to $40.7 \%$ (The COVID-19 global rheumatology alliance global registry, 2020). Other studies are in agreement with this observation and exhibited that SARS-CoV-2 infection is more prevalent in RA patients [24]. Immunosuppressant therapy was seen to be considerably associated with the risk of SARS-CoV-2 infection [22]. In contrast, a Euro-COVIMID cross-sectional study interpreted that neither immune-mediated inflammatory diseases nor immunosuppressant therapy could produce any significant change in COVID-19 severity and mortality as compared to general population [22]. Simmon and colleagues claimed that treatment with anticytokine drugs represent low prevalence of COVID-19 seroconversion to the patients with immune-mediated inflammatory diseases [25]. However, this protective mechanism is yet to be clearly deciphered.

\subsection{Can RA worsen COVID-19 outcomes?}

OpenSAFELY-a health analytics platform holding healthcare records of $40 \%$ patients in England revealed that presence of rheumatic diseases slightly increased risk of COVID19 mortality as compared with the patients without these diseases [26]. In a recent UK Biobank cohort analysis, Topless and colleagues (2021) revealed that RA is a potential risk factor in COVID-19-related death [27]. RA patients more likely represent comorbidities like asthma, chronic obstructive pulmonary disease, hypertension, cardiovascular diseases, and diabetes [28]. Thus, RA patients are always at the high risk of COVID-19 severity and death as compared to the patients without RA. RA medication can also contribute in COVID-19 outcomes. In a prospective study involving 103 patients with inflammatory arthritis (RA and spondyloarthritis), Haberman and colleagues (2020) conferred that immunosuppressant therapy can worsen COVID-19 outcomes as compared to the patients receiving cytokine inhibitors [29]. Similar 
observations have been reported by others [7]. Moreover, it was demonstrated that RA can also be worsened by infection through iatrogenic effect of immunosuppressants [7].

\section{Immune-inflammatory activities in SARS-CoV-2 infection and RA}

Upon SARS-CoV-2 infection, infected host cells rapidly execute both innate and adaptive immune responses, which serve as the initial line of defense against COVID19 [30] (Fig. 1A). CD8+ cytotoxic T lymphocytes can recognize SARS-CoV-2 structural proteins presented by infected epithelial cells and induce apoptosis to virus-targeted cells by releasing proapoptotic factors, such as perforin and granzymes [31]. CD4+ helper $T$ cells contribute to overall adaptive response by assisting cytotoxic $T$ cells. Upon infection CD4+ helper $T$ cells recruit $T$ helper (Th) 1 cells and endorse differentiation of $B$ lymphocytes into plasma cells which in turn produce specific antiSARS-CoV-2 specific antibodies [31]. In addition, CD4+ and CD8+ T cells produce type I interferon (IFN) which acts together with antiviral antibodies to neutralize SARS-CoV-2 [30] (Fig. 1A). However, $T$ cell-mediated immune responses depend on antigen presenting cell (APC)-mediated cytokine microenvironment. Dysfunctional immune response in association with lymphopenia yield severe pulmonary, other systemic injuries, and potentially death by endorsing hyperinflammatory state mediated through the massive release of cytokine and chemokines in excess [30]. This phenomenon is referred as cytokine storm. SARS-CoV-2 can trigger caspase 1 activation via upregulating NLR family pyrin domain containing 3 (NLRP3) inflammasome, which subsequently induces pyroptosis to the lymphocytes through recruiting IL-1 $1 \beta$ and IL-18 [32] (Fig. 1B). Significant decrease in the number of memory $T$ helper cells and regulatory $T$ lymphocytes has been reported in COVID-19 patients [30]. Immunological basis of severe COVID-19 pathogenesis could be associated with development of pathogenic $\mathrm{T}$ cell phenotypes and massive production of proinflammatory mediators. SARS-CoV-2 infection can divert the commitment of CD4+ $T$ lymphocytes towards a pathogenic Th1 cell immunophenotypes resulting in the release of pro-inflammatory cytokines, such as IL-6 and granulocyte-macrophage colony-stimulating factor (GMCSF) [33]. This hyperinflammatory milieu can subsequently endorse differentiation of monocytes into macrophages or APC by further secreting IL-6 [33]. Excess of systemic 
IL-6 endorses C-reactive protein production, impairs immunophysiological function of Th1 cells against SARS-CoV-2, and inhibits physiologic actions of CD8+ T and natural killer (NK) cells [30] (Fig. 1B). After penetration into lung tissue, SARS-CoV-2 reaches to APC and endorses differentiation of Th0 cells into Th17 lymphocytes which subsequently trigger IL-17 production. IL-17 subsequently endorses macrophage activation and neutrophil recruitment, which subsequently promote neutrophilic inflammation and suppress adaptive immune responses against virus [30]. Several comorbidities favour this immunopathological swing of Th17/LL-17 hyperactivation in COVID-19 patients [34] (Fig. 1B). Emerging evidence revealed that an elevated levels of plasma cytokines, such as IL-1 $\beta$, IL-2, IL-4, IL-6, IL-7, IL-10, IL-17, IL-18, TNF- $\alpha$, vascular endothelial growth factor (VEGF), granulocyte-macrophage colony-stimulating factor (GM-CSF), IFN- $\gamma$, etc. and chemokines (CXCL-8, CXCL-10, CCL-1, CCL-2, CCL3, CCL-4 etc.) are directly associated with COVID-19 severity [35] [36].

Immunologically, RA is characterized by dysfunctional innate immunity, adaptive immunity against 'self'-antigens, and dysregulation in cytokine set-ups. CD4+ T cells contribute to the chronic autoimmune response of RA via antigenic activation of naive CD8+ $T$ cells, which in turn, triggers inflammation via massive production of proinflammatory mediators [37] (Fig. 2). TNF- $\alpha$, IL-1 $\beta$, and IL-6 play crucial roles in stimulating joint inflammation in RA [38]. The role of CD4+ T-cells in chronic inflammation in RA has been revealed [37]. Emerging evidence discovered the predominant role of Th cells in the pathogenesis of RA [39]. Th1 hyperactivation in RA triggers the secretion of pro-inflammatory mediators, such as IFN- $\gamma$, IL-2, and TNF- $\alpha$ [39]. In addition, Th1 cells can recruit macrophages to act as APC. Th2 cells also play critical roles in RA pathogenesis, which promote $B$ lymphocyte differentiation to produce antibody (IgE) [37]. Th17/IL-17 axis also plays a central role in RA pathogenesis [37]. IL-17 enhances the production of IL-6, IL-8, VEGF-A, and matrix metalloproteinases (MMP-1 and -3) in RA synovial fibroblasts [37] (Fig. 2). Enhanced plasma level of proinflammatory cytokines (IL-1 $\beta$, IL-2, IL-4, IL-6, IL-7, IL-12, IL-16, IL-17, IL-18, TNF- $\alpha$, GM-CSF, IFN-y etc.) and chemokines (CXCL-8, CXCL-10, CCL-1, CCL-2, CCL-3, CCL4 , CCL-5 etc.) remain diagnostic feature in RA patients [40]. Thus, aberration in immune 
response resulting in hyperactivation of pro-inflammatory cytokine-chemokine axis play crucial role in the pathogenesis of both SARS-CoV-2 infection and RA.

\section{Mechanistic similarity between SARS-CoV-2 infection and RA}

\subsection{Angiotensin-converting enzyme (ACE)-dependent pathway}

Immune-inflammatory disorders can be associated with ACE/ACE2 [41]. The role of ACE2 in SARS-CoV-2 infection stands itself as an irony. ACE2 as a receptor serves as a potential cellular target for SARS-CoV-2 to enter the target cells [42] (Fig. 3). Binding of ACE2 by SARS-CoV-2 is central for its host cell entry, however, recent evidences revealed a key role of heparan sulfate in facilitating their interaction and thereby potentiating SARS-CoV-2 cell entry and infection [43] [44]. In contrast, ACE2 as an enzyme plays protective role in SARS-CoV-2 infection [42]. The S-protein of SAR-CoV2 binds to ACE2 resulting a suppression of ACE2 expression and promote COVID-19 pathogenesis [45]. ACE2 catalyzes the conversion of angiotensin II to angiotensin-1-7. Inhibition of ACE2/angiotensin-1-7/Mas activates renin-angiotensin system (Ras)/rapidly accelerated fibrosarcoma (Raf)/mitogen-activated protein kinase (MAPK) cascade, which in turn shares identical pathological signalling in both COVID-19 and RA [46] (Fig. 3). ACE2 activators have been regarded to provide dual benefits in COVID-19 treatment: firstly, by inhibiting the binding of S-protein of SARS-CoV-2 to ACE2, and secondly by offering the protective effect of the ACE2 enzyme [47]. In inflammatory milieu, angiotensin $\mathrm{II}$ is known to endorse inflammatory responses and vascular permeability by enhancing the production of prostaglandins and VEGF [48]. These inflammatory mediators further endorse nuclear factor kappa-light-chain-enhancer of activated $\mathrm{B}$ cells (NF-KB) signalling and intensify the inflammatory responses and infiltration of inflammatory cells into damaged tissues [48]. ACE promotes the conversion of angiotensin I to angiotensin II. Thus, ACE could be pathologically involved in both SAR-CoV-2 infection and RA. ACE inhibitors were found to limit the production of pro-inflammatory cytokines by monocytes and APC through suppressing NF-KB activation [48]. ACE inhibitors have been proven to improve vascular endothelial function in RA patients [49]. Similarly, pharmacological inhibition of ACE and 
angiotensin II has been reported to reduce the risk of mortality in COVID-19 patients [50].

\subsection{Macrophage-mediated pathway}

Macrophages present in bronchial and synovial tissues are heterogeneous (Fig. 4). Healthy lung representing fatty acid binding protein 4 (FABP4)-positive alveolar macrophages help in maintaining gas exchange and compliance. During SARS-CoV-2 infection, numbers of FABP4-positive alveolar macrophages is substantially reduced, and thus gas exchange is compromised [51] (Fig. 4). COVID-19 patients abundantly represent two distinct macrophage clusters expressing of ficolin-1 (FCN1), namely FCNpositive and both FCN and SPP1-positive macrophages, however their pathological role is yet to be established. Similarly, synovial tissue also represents distinct macrophage subsets in RA patients as compared to healthy people [52] (Fig. 4). Healthy synovial tissue lining represents macrophage clusters expressing triggering receptor expressed on myeloid cells 2 (TREM2) with a contribution of folate receptor beta (FOLR2) and lymphatic vessel endothelial hyaluronan receptor 1 (LYVE1). The macrophages in synovial sub-lining express FOLR2 with a contribution of LYVE1, inhibitor of DNA binding 2, and intercellular adhesion molecule 1. As compared to healthy joints, synovial tissue of RA patients additionally represents CD48-high-S100A12-positive and CD48positive-SPP1-positive macrophage clusters, which have been revealed to be associated in RA pathogenesis via producing inflammatory mediators such as IL-1 $\beta$, IL6, TNF- $\alpha$, MMPs, and chemokines [53]. FCN-positive and FCN-positive-SPP1-positive macrophages in bronchoalveolar lavage fluid share transcriptional homology with pathogenic CD48-high-S100A12-positive and CD48-positive-SPP1-positive macrophages in synovial tissue [53]. In addition, both share similar functional characteristics in the respective tissues [53]. Similarly, FABP4 expressing alveolar macrophages share transcriptional and functional homology with TREM2-positive synovial macrophages [53]. Thus, bronchoalveolar immune-inflammation pathway in SARS-CoV-2 infection shares similar mechanism as seen in synovial tissue in RA (Fig. 4). 


\section{Therapeutic management and challenges}

\subsection{Recommendation for anti-rheumatic drugs in the COVID-19 setting}

Patients with RA generally represent compromised immune system, which makes them susceptible to SARS-CoV-2 infection [24]. Treatment with immunosuppressant drugs further increases the risk of acquiring SARS-CoV-2 infection [22]. In addition, clinical symptoms between RA flares and SARS-CoV-2 infection frequently overlap [28]. Both RA and COVID-19-positive patients represent the symptoms like arthralgia, myalgia and other inflammatory disorders. RA-mediated interstitial lung disease also mimics COVID19 symptoms. Moreover, RA patients frequently represent increasing evidence of comorbidities [54]. Thus, clinical management of RA itself stands as a challenging task in the present COVID-19 setting. Among the possible therapeutic options, the American college of rheumatology (ACR) and the European league against rheumatism (EULAR) recommended several guidelines regarding the use of RA medication in the COVID-19 pandemic [55] [56]. Glucocorticoids have been recommended at the lowest possible dose even in COVID-19-positive cases; however, sudden withdrawal is not recommended. Non-steroidal anti-inflammatory drug (NSAIDs) can be continued unless severe COVID-19 manifestations to various organs. Conventional synthetic diseasemodifying antirheumatic drugs (csDMARDs) can be used; however, leflunomide, methotrexate, and sulfasalazine are recommended to be avoided in suspected or confirmed COVID-19 patients. Except for IL-6 inhibitors, all biological DMARDs (bDMARDs) or targeted synthetic DMARDs (tsDMARDs) should be stopped in suspected or confirmed cases of COVID-19. Regarding re-initiation of DMARDs, ACR recommended for restarting these drugs within 7-14 days of symptom resolution and within 10-17 days of positive report for symptomatic and asymptomatic patients, respectively [55]. However, treatment resumption requires on an individual basis for patients recuperating from a serious illness [55].

\subsection{Challenges with anti-rheumatic agents in the COVID-19 setting}

Despite no direct association has been established between specific RA medication and the COVID-19 development or outcomes, some reports showed that RA patients exhibit 
an increased risk of serious infections (Table 1). Accumulating evidence claimed the protective role of glucocorticoids in COVID-19 disease, which is predominantly mediated through their immunosuppressive effects to overturn hyperinflammation in the late phases of SARS-CoV-2 infection [28] ). World health organization (WHO) recommended glucocorticoid treatment in severe/critical COVID-19 cases. In contrast, Russell and colleagues (2020) claimed that corticosteroids are not clinically effective in COVID-19 lung injury [57]. Moreover, moderate to high-dose glucocorticoids can increase the risk of poor outcomes [58]. In a small cohort, Haberman and colleagues (2020) also found that glucocorticoid treatment worsens COVID-19 outcomes in patients with inflammatory arthritis [29]. According to the Global rheumatology alliance and other reports, glucocorticoid ( $\geq 10 \mathrm{mg} /$ day) is associated with an increased rate of hospitalization for COVID-19 in patients with rheumatic diseases [23]. In this aspect, glucocorticoid dose and disease status have been regarded as two potential risk factors for COVID-19 severity in patients with rheumatic diseases [59]. RA patients chronically receiving glucocorticoids have been recommended to avoid sudden withdrawal of steroids and to continue their treatment with the lowest possible doses [24]. Thus, the dose of a glucocorticoid stands critical in this aspect.

Some reports claimed that the use of NSAIDs does not produce any serious adverse manifestation in COVID-19 patients [60] (Table 1). Australian rheumatology association and the national institute for health and clinical excellence (NICE) guidelines recommended that RA patients with long-term treatment with NSAIDs may continue their medication in the COVID-19 setting [28]. However, ACR recommended stopping NSAIDs in the cases of severe COVID manifestations [28]. However, the role of NSAIDs in the course of viral infections is still controversial. Recent preclinical data showed that although NSAIDs could suppress the inflammatory response in SARSCoV-2 infection; but, they simultaneously impaired humoral immune response against SARS-CoV-2 infection by dampening the production of protective antibodies [61]. In another preclinical study of cardiac fibrosis in diabetic rats, ibuprofen has been found to activate ACE2 [62] which serves as a gateway for SARS-CoV-2 infection [63]. In addition, ibuprofen and ketoprofen can aggravate the risk of bacterial infections [64]. French society of pharmacology, therapeutics recommended that the use of NSAIDs 
should be avoided for symptomatic treatment in non-severe COVID-19 cases [64]. In a recent retrospective, multi-center observational study, non-selective COX inhibitors (aspirin and acetaminophen) were found to be associated with increased severity and mortality in COVID-19 patients including the patients with preexisting arthritis [65]. Fever is regarded as one of the indications of SARS-CoV-2 infection. Thus, the use of NSAIDs in the COVID-19 setting may delay in diagnosis of SARS-CoV-2 infection due to their antipyretic principle. However, treatment with selective COX-2 inhibitors (diclofenac, meloxicam and celecoxib) was not associated with an increase in COVID-19 severity [65]. Thus, it may be said that the effect of NSAIDs represents agent-specific risk profiles for an individual compound in the COVID-19 setting.

Hydroxychloroquine and chloroquine are commonly used as csDMARDs directed for the treatment of RA. Both fulfill theoretical requirements for being effective against SARSCoV-2 infection [66]. Thus, these antimalarial drugs were initially included in COVID-19 management. However, their effects remain controversial in COVID-19 management, and difference set of observations were reported in different clinical studies [1]. According to a previous report, these agents are not only effective but also have the potential to cause more harm than benefit [28]. Patients chronically treated with hydroxychloroquine or chloroquine as anti-RA drugs before COVID-19 pandemic did not exhibit any difference in COVID-19 outcomes compared to the patients who do not receive these antimalarial drugs [67]. Increasing evidence of COVID-19 death has been observed due to cardio-toxic effect (arrhythmia) of drugs used in the treatment of COVID-19 disease [68]. Chloroquine and hydroxychloroquine treatment has been regarded to develop QT prolongation in almost $10 \%$ of COVID-19 patients [1]. Thus, WHO recommended against the use of hydroxychloroquine and chloroquine for COVID19 treatment [69]. ACR also suggested a temporary suspension of hydroxychloroquine and chloroquine for RA patients in the setting of SARS-CoV-2 infection [68]. Similarly, the use of other csDMARD, such as leflunomide, methotrexate, and sulfasalazine has been recommended to withdraw momentarily in RA patients during active SARS-CoV-2 infection (Table 1). 
Considering the mechanistic similarity between RA and COVID-19 disease pathogenesis, it has been postulated that bDMARDs would be effective in the COVID19 setting. However, the effect of bDMARDs in the COVID-19 setting remains highly controversial (Table 1). According to the national health service (NHS) England, RA patients treated with bDMARDs, such as tocilizumab, rituximab, and TNF inhibitors increase the risk of acquiring SARS-CoV-2 infection compared to the patients treated with csDMARDs [28]. In contrast, others were not in agreement with the claim of NHS [24]. According to the data from GRA global registry, out of 7263 COVID-19 positive cases among rheumatic patients, $2188(30.13 \%)$ patients were under the treatment with bDMARDs (The COVID-19 global rheumatology alliance global registry, 2020). Now coming to the continuation of bDMARDs in rheumatic patients with COVID-19 condition, anti-TNF therapy has been found to lower the disease severity and mortality [70]. GRA global registry data also claimed that using bDMARDs treatment (largest subgroup used TNF inhibitors, 52\%) by rheumatic patients before COVID-19 significantly decreases the risk of hospitalization (The COVID-19 global rheumatology alliance global registry, 2020). Anti-IL-6 (tocilizumab) treatment also had positive or equivocal results on COVID-19 outcomes [71]. In spite of, some medical societies recommended against the start or continuation of bDMARDs, including anti-TNF treatment, in the places where COVID-19 has been circulating in the community, though the use of anti-IL-6 agents has considered safer [72]. The tendency of anti-TNF drugs to increase viral infection risk has been considered in this aspect. The risk of severe and opportunistic infections in RA patients under the treatment of tsDMARDs is roughly similar to that of bDMARDs in COVID-19 [73]. Among tsDMARDs, janus kinase (JAK) inhibitors, such as baricitinib, tofacitinib, and upadacitinib were studied in different trials [73]. Emerging evidence revealed that JAK inhibitors could possibly increase the risk of venous thromboembolism [74]. JAK inhibitors were also found to impair IFN-mediated anti-viral response and increase the risk of secondary infection [73]. Thus, medical associations recommended for a temporary suspension of tsDMARDs to RA patients following COVID-19 exposure. Precautionary withdrawal of DMARDs could simultaneously raise the chance of disease relapse and morbid outcomes in rheumatic patients [75]. Thus, it 
would be a challenging task for the rheumatologists to treat the patients who were under DMARD treatment before COVID-19.

\subsection{Monitoring RA patients in the COVID-19 setting}

In the ongoing COVID-19 pandemic, monitoring of RA patients is a big challenge for rheumatologists. Patients with RA are known to be more susceptible to a multitude of infections, which advises against physical visiting physicians in a routine manner. The COVID-19 lockdown also aids in this issue. Thus, in absence of routine clinical assessment, it is really a challenging task for the rheumatologists to follow effective disease control protocol to alleviate disease activity. So, the situation forced rheumatologists to develop effective strategies to provide optimum patient care. Recent reports showed that telemedicine is gaining popularity in this situation [76]. It allows patients with stable disease conditions to reduce their visits to the clinics through adopting virtual consultation with rheumatologists. In India, rheumatologists were found to use voice-over-IP service more frequently followed by video consultations and emails to provide virtual care [77]. Telephonic consultations supported by supplemental information, such as laboratory tests and photos of suspected manifestation areas were also found to be helpful to avoid physical visits [78]. In this aspect, RA impact of disease score, a patient-derived score covering seven health areas: pain, fatigue, functional capacity, sleep quality, coping, physical well-being, and emotional well-being has gained reasonable confidence of rheumatologists for the virtual clinic to assess a composite measure of disease activity [79]. Flare assessment in RA questionnaire, a self-reported flare can also serve as a potential tool in telehealth follow-up with rheumatologists [80]. However, these teleconsultations do not allow proper clinical examinations, which is critical for a precise diagnosis. Since it is difficult to anticipate when ongoing pandemic will end, rheumatologists must put in extra effort to build an appropriate telemedicine system that will provide high-quality healthcare and continuity of care for RA patients. In general, patients with stable disease activity could be advised to reduce their visits to clinics and to ensure virtual or teleconsultation, if required. However, patients who require frequent visits to the clinics for their disease severity, other therapeutic requirements, or in case of emergency could be advised to take all 
precautionary measures to avoid acquiring infection or to stop spreading the infection (for COVID-19 positive RA patients).

\section{Conclusion}

The clinical features of pro-inflammatory cytokines/mediators produced from the SARSCoV-2 infected alveolar structures in COVID-19 share resemblance with hyper immunoreactive features of RA. In both conditions, acute localized inflammation in the designated tissue induces localized damage and reactivity that may lead to organ failure. The SARS-CoV-2 elicited pro-inflammatory cytokines cause alveolar epithelial cell damage by profoundly activating $T$ cell response in the lungs. It triggers exaggerated local inflammation that attracted a large population of macrophages and neutrophils to the lungs. Among these events, damage of tissue lining, T cell activation, pro-inflammatory cytokine release and elevated neutrophil influx are key immunopathological features that share common mediators between COVID-19 and RA. Given the profound pro-inflammatory activity of IL-1 $\beta$, IL-6, IFN- $\gamma$, IL-2, and TNF- $\alpha$ cytokines in COVID-19, it produces a systemic acute-phase response that is often seen in RA. We here provided insights into the severity and risk of COVID-19 to RA patients, and also reported contradictory clinical evidence obtained in RA patients. Besides the overlapping COVID-19 and RA clinical features, we shed light on the diverse aspects of SARS-CoV-2 infection in RA development and concomitant risks. With the growing speculations that RA can worsen COVID-19 outcome as well, we reviewed the emerging links of ACE-dependent and macrophage-mediated pathways to gain mechanistic insight into the overlapping immune-inflammatory features in SARS-CoV-2 infection and RA. Towards an effective therapeutic management, we provided a comprehensive review of favoring and contraindication anti-rheumatic drugs including the NSAIDs, csDMARDs, bDMARDs, and tsDMARDs in the COVID-19 setting. Although these anti-rheumatic drugs showed promise in certain clinical settings, a precise utility of their targeted inhibition in SARS-CoV-2 infected RA patient's further warrants careful investigations. Recognition of pathological hyper-inflammatory state in 
the SARS-CoV-2 infected RA patients largely underlined the need for anti-rheumatic and anti-cytokine drugs; however, advice to RA patients on whether to stop or continue anti-RA drugs requires careful testing of all disease-related parameters including severity, age, and comorbidities. Given the fact diverse anti-rheumatic drugs (NSAIDs, csDMARDs, bDMARDs, and tsDMARDs) do not elevate COVID-19 severity/risk; RA patients may continue taking anti-rheumatic drugs during the pandemic. In this line, we identified the immediate challenges and forwarded key recommendations for the usage of anti-rheumatic drugs in the COVID-19 setting for better clinical monitoring and management of RA patients. Conclusively, here we summarized the recent evidence on the emerging COVID-19 and RA crosstalk and their shared mechanistic features and therapeutic options.

\section{Author's contribution}

SD and RK contributed to the conceptualization and designing the manuscript. RKS, JV, AR, CSV, VK and PHR edited and corrected the manuscript. The final correction and editing were done by SD, RKS, RK, and, PHR.

\section{Declaration of Competing Interest}

The authors declare no conflict of interest.

\section{Acknowledgments}

The authors are thankful to the Council of Scientific and Industrial Research, New Delhi, India, for awarding the research project (grant number 02(0275)/16/EMR-II) to SD. The authors sincerely acknowledge Jadavpur University, India for providing necessary facilities. RK acknowledged DBT, India for Ramalingaswami Fellowship (NO. BT/RLF/Re-entry/22/2016 and SAN.No. 102/IFD/SAN/1117/2018-19), Kakatiya Medical College, Warangal, and CSIRIICT (IICT/Pubs./2021/099), Hyderabad. Authors are thankful to National Institutes of Health (NIH) grants USA, AG042178, AG047812, NS105473, AG060767, AG069333, AG066347, and R41 AG060836 to PHR. 


\section{References:}

[1] R.S. Kalra, D. Tomar, A.S. Meena, R. Kandimalla, SARS-CoV-2, ACE2, and Hydroxychloroquine: Cardiovascular Complications, Therapeutics, and Clinical Readouts in the Current Settings, Pathogens, 9 (2020).

[2] G. Schett, B. Manger, D. Simon, R. Caporali, COVID-19 revisiting inflammatory pathways of arthritis, Nat Rev Rheumatol, 16 (2020) 465-470.

[3] R.S. Kalra, J.K. Dhanjal, A.S. Meena, V.C. Kalel, S. Dahiya, B. Singh, S. Dewanjee, R. Kandimalla, COVID-19, Neuropathology, and Aging: SARS-CoV-2 Neurological Infection, Mechanism, and Associated Complications, Front Aging Neurosci, 13 (2021) 662786.

[4] M.S. Mukarram, M. Ishaq Ghauri, S. Sethar, N. Afsar, A. Riaz, K. Ishaq, COVID-19: An Emerging Culprit of Inflammatory Arthritis, Case Rep Rheumatol, 2021 (2021) 6610340.

[5] S.V. Dewanjee, J.; Kalra, R. S.; Puvvada, N.; Kandimalla, R.; \& Reddy, P. H., Emerging COVID-19 Neurological Manifestations: Present Outlook and Potential Neurological Challenges in COVID-19 Pandemic, Molecular neurobiology, Epub ahead of print. (2021).

[6] Y.B. Joo, Y.H. Lim, K.J. Kim, K.S. Park, Y.J. Park, Respiratory viral infections and the risk of rheumatoid arthritis, Arthritis Res Ther, 21 (2019) 199.

[7] E.G. Favalli, F. Ingegnoli, O. De Lucia, G. Cincinelli, R. Cimaz, R. Caporali, COVID19 infection and rheumatoid arthritis: Faraway, so close!, Autoimmun Rev, 19 (2020) 102523.

[8] K.M. D'Silva, Z.S. Wallace, COVID-19 and rheumatoid arthritis, Curr Opin Rheumatol, 33 (2021) 255-261. 
[9] N.P. Disser, A.J. De Micheli, M.M. Schonk, M.A. Konnaris, A.N. Piacentini, D.L. Edon, B.G. Toresdahl, S.A. Rodeo, E.K. Casey, C.L. Mendias, Musculoskeletal Consequences of COVID-19, J Bone Joint Surg Am, 102 (2020) 1197-1204.

[10] S.L. Ramani, J. Samet, C.K. Franz, C. Hsieh, C.V. Nguyen, C. Horbinski, S. Deshmukh, Musculoskeletal involvement of COVID-19: review of imaging, Skeletal Radiol, (2021).

[11] Y. Huang, M. Tu, S. Wang, S. Chen, W. Zhou, D. Chen, L. Zhou, M. Wang, Y. Zhao, W. Zeng, Q. Huang, H. Xu, Z. Liu, L. Guo, Clinical characteristics of laboratory confirmed positive cases of SARS-CoV-2 infection in Wuhan, China: A retrospective single center analysis, Travel Med Infect Dis, 36 (2020) 101606.

[12] B. Zhang, S. Zhang, Corticosteroid-Induced Osteonecrosis in COVID-19: A Call For Caution, J Bone Miner Res, 35 (2020) 1828-1829.

[13] M.M. Steinz, E. Santos-Alves, J.T. Lanner, Skeletal muscle redox signaling in rheumatoid arthritis, Clin Sci (Lond), 134 (2020) 2835-2850.

[14] R. Vaishya, V.K. Jain, K.P. lyengar, Musculoskeletal manifestations of COVID-19, J Clin Orthop Trauma, 17 (2021) 280-281.

[15] A. Carfi, R. Bernabei, F. Landi, C.-P.-A.C.S.G. Gemelli Against, Persistent Symptoms in Patients After Acute COVID-19, JAMA, 324 (2020) 603-605.

[16] K.T. Tang, B.C. Hsu, D.Y. Chen, Autoimmune and Rheumatic Manifestations Associated With COVID-19 in Adults: An Updated Systematic Review, Front Immunol, 12 (2021) 645013.

[17] S. Parisi, R. Borrelli, S. Bianchi, E. Fusaro, Viral arthritis and COVID-19, Lancet Rheumatol, 2 (2020) e655-e657.

[18] V. Derksen, T. Kissel, F.B.G. Lamers-Karnebeek, A.E. van der Bijl, A.C. Venhuizen, T.W.J. Huizinga, R.E.M. Toes, A.H.E. Roukens, D. van der Woude, Onset of 
rheumatoid arthritis after COVID-19: coincidence or connected?, Ann Rheum Dis, (2021).

[19] L. Perrot, M. Hemon, J.M. Busnel, O. Muis-Pistor, C. Picard, C. Zandotti, T. Pham, J. Roudier, S. Desplat-Jego, N. Balandraud, First flare of ACPA-positive rheumatoid arthritis after SARS-CoV-2 infection, Lancet Rheumatol, 3 (2021) e6-e8.

[20] R. Roongta, A. Chattopadhyay, A. Ghosh, Correspondence on 'Onset of rheumatoid arthritis after COVID-19: coincidence or connected?', Ann Rheum Dis, (2021).

[21] D. Saadoun, M. Vieira, M. Vautier, X. Baraliakos, I. Andreica, J.A.P. da Silva, M. Sousa, M. Luis, N. Khmelinskii, J.M.A. Gracia, I. Castrejon, J.C.N. Gonzalez, C.A. Scire, E. Silvagni, A. Bortoluzzi, H. Penn, S. Hamdulay, P.M. Machado, B. Fautrel, P. Cacoub, M. Resche-Rigon, L. Gossec, SARS-CoV-2 outbreak in immune-mediated inflammatory diseases: the Euro-COVIMID multicentre cross-sectional study, Lancet Rheumatol, (2021).

[22] S. Akiyama, S. Hamdeh, D. Micic, A. Sakuraba, Prevalence and clinical outcomes of COVID-19 in patients with autoimmune diseases: a systematic review and metaanalysis, Ann Rheum Dis, (2020).

[23] K.L. Hyrich, P.M. Machado, Rheumatic disease and COVID-19: epidemiology and outcomes, Nat Rev Rheumatol, 17 (2021) 71-72.

[24] E.G. Favalli, G. Maioli, M. Biggioggero, R. Caporali, Clinical management of patients with rheumatoid arthritis during the COVID-19 pandemic, Expert Rev Clin Immunol, (2021) 1-11.

[25] D. Simon, K. Tascilar, G. Kronke, A. Kleyer, M.M. Zaiss, F. Heppt, C. Meder, R. Atreya, E. Klenske, P. Dietrich, A. Abdullah, T. Kliem, G. Corte, H. Morf, M. Leppkes, A.E. Kremer, A. Ramming, M. Pachowsky, F. Schuch, M. Ronneberger, S. Kleinert, C. Maier, A.J. Hueber, K. Manger, B. Manger, C. Berking, M. Tenbusch, K. Uberla, M. 
Sticherling, M.F. Neurath, G. Schett, Patients with immune-mediated inflammatory diseases receiving cytokine inhibitors have low prevalence of SARS-CoV-2 seroconversion, Nat Commun, 11 (2020) 3774.

[26] E.J. Williamson, A.J. Walker, K. Bhaskaran, S. Bacon, C. Bates, C.E. Morton, H.J. Curtis, A. Mehrkar, D. Evans, P. Inglesby, J. Cockburn, H.I. McDonald, B. MacKenna, L. Tomlinson, I.J. Douglas, C.T. Rentsch, R. Mathur, A.Y.S. Wong, R. Grieve, D. Harrison, H. Forbes, A. Schultze, R. Croker, J. Parry, F. Hester, S. Harper, R. Perera, S.J.W. Evans, L. Smeeth, B. Goldacre, Factors associated with COVID-19-related death using OpenSAFELY, Nature, 584 (2020) 430-436.

[27] R.K. Topless, A. Phipps-Green, M. Leask, N. Dalbeth, L.K. Stamp, P.C. Robinson, T.R. Merriman, Gout, Rheumatoid Arthritis, and the Risk of Death Related to Coronavirus Disease 2019: An Analysis of the UK Biobank, ACR Open Rheumatol, 3 (2021) 333-340.

[28] R. Roongta, A. Ghosh, Managing rheumatoid arthritis during COVID-19, Clin Rheumatol, 39 (2020) 3237-3244.

[29] R.H. Haberman, R. Castillo, A. Chen, D. Yan, D. Ramirez, V. Sekar, R. Lesser, G. Solomon, A.L. Neimann, R.B. Blank, P. Izmirly, D.E. Webster, A. Ogdie, A.B. Troxel, S. Adhikari, J.U. Scher, N.W. Investigators, COVID-19 in Patients With Inflammatory Arthritis: A Prospective Study on the Effects of Comorbidities and Disease-Modifying Antirheumatic Drugs on Clinical Outcomes, Arthritis Rheumatol, 72 (2020) 1981-1989.

[30] C. Pelaia, C. Calabrese, E. Garofalo, A. Bruni, A. Vatrella, G. Pelaia, Therapeutic Role of Tocilizumab in SARS-CoV-2-Induced Cytokine Storm: Rationale and Current Evidence, Int J Mol Sci, 22 (2021).

[31] A.K. Azkur, M. Akdis, D. Azkur, M. Sokolowska, W. van de Veen, M.C. Bruggen, L. O'Mahony, Y. Gao, K. Nadeau, C.A. Akdis, Immune response to SARS-CoV-2 and mechanisms of immunopathological changes in COVID-19, Allergy, 75 (2020) 15641581. 
[32] M.Z. Ratajczak, M. Kucia, SARS-CoV-2 infection and overactivation of Nlrp3 inflammasome as a trigger of cytokine "storm" and risk factor for damage of hematopoietic stem cells, Leukemia, 34 (2020) 1726-1729.

[33] Y.F. Zhou, Binqing.; Zheng, Xiaohu., Wang, Dongsheng., Zhao, Changcheng., qi, Yingjie., Sun, Rui.; Tian, Zhigang.; Xu, Xiaoling.; Wei, Haiming., Pathogenic T-cells and inflammatory monocytes incite inflammatory storms in severe COVID-19 patients, National Science Review, 7 (2020) 998-1002.

[34] M. Orlov, P.L. Wander, E.D. Morrell, C. Mikacenic, M.M. Wurfel, A Case for Targeting Th17 Cells and IL-17A in SARS-CoV-2 Infections, J Immunol, 205 (2020) 892-898.

[35] V.J. Costela-Ruiz, R. Illescas-Montes, J.M. Puerta-Puerta, C. Ruiz, L. MelguizoRodriguez, SARS-CoV-2 infection: The role of cytokines in COVID-19 disease, Cytokine Growth Factor Rev, 54 (2020) 62-75.

[36] A. Pum, M. Ennemoser, T. Adage, A.J. Kungl, Cytokines and Chemokines in SARS-CoV-2 Infections-Therapeutic Strategies Targeting Cytokine Storm, Biomolecules, 11 (2021).

[37] H.Y. Yap, S.Z. Tee, M.M. Wong, S.K. Chow, S.C. Peh, S.Y. Teow, Pathogenic Role of Immune Cells in Rheumatoid Arthritis: Implications in Clinical Treatment and Biomarker Development, Cells, 7 (2018).

[38] Y. Araki, T. Mimura, The Mechanisms Underlying Chronic Inflammation in Rheumatoid Arthritis from the Perspective of the Epigenetic Landscape, J Immunol Res, 2016 (2016) 6290682.

[39] N. Meednu, H. Zhang, T. Owen, W. Sun, V. Wang, C. Cistrone, J. Rangel-Moreno, L. Xing, J.H. Anolik, Production of RANKL by Memory B Cells: A Link Between B Cells and Bone Erosion in Rheumatoid Arthritis, Arthritis Rheumatol, 68 (2016) 805-816. 
[40] N.M. Elemam, S. Hannawi, A.A. Maghazachi, Role of Chemokines and Chemokine Receptors in Rheumatoid Arthritis, Immunotargets Ther, 9 (2020) 43-56.

[41] Z. Zhu, T. Cai, L. Fan, K. Lou, X. Hua, Z. Huang, G. Gao, The potential role of serum angiotensin-converting enzyme in coronavirus disease 2019, BMC Infect Dis, 20 (2020) 883.

[42] W. Ni, X. Yang, D. Yang, J. Bao, R. Li, Y. Xiao, C. Hou, H. Wang, J. Liu, D. Yang, Y. Xu, Z. Cao, Z. Gao, Role of angiotensin-converting enzyme 2 (ACE2) in COVID-19, Crit Care, 24 (2020) 422.

[43] T.M. Clausen, D.R. Sandoval, C.B. Spliid, J. Pihl, H.R. Perrett, C.D. Painter, A. Narayanan, S.A. Majowicz, E.M. Kwong, R.N. McVicar, B.E. Thacker, C.A. Glass, Z. Yang, J.L. Torres, G.J. Golden, P.L. Bartels, R.N. Porell, A.F. Garretson, L. Laubach, J. Feldman, X. Yin, Y. Pu, B.M. Hauser, T.M. Caradonna, B.P. Kellman, C. Martino, P. Gordts, S.K. Chanda, A.G. Schmidt, K. Godula, S.L. Leibel, J. Jose, K.D. Corbett, A.B. Ward, A.F. Carlin, J.D. Esko, SARS-CoV-2 Infection Depends on Cellular Heparan Sulfate and ACE2, Cell, 183 (2020) 1043-1057 e1015.

[44] R.S. Kalra, R. Kandimalla, Engaging the spikes: heparan sulfate facilitates SARSCoV-2 spike protein binding to ACE2 and potentiates viral infection, Signal Transduct Target Ther, 6 (2021) 39.

[45] S. Choudhary, K. Sharma, O. Silakari, The interplay between inflammatory pathways and COVID-19: A critical review on pathogenesis and therapeutic options, Microb Pathog, 150 (2021) 104673.

[46] R.S. Kalra, V. Kumar, J.K. Dhanjal, S. Garg, X. Li, S.C. Kaul, D. Sundar, R. Wadhwa, COVID19-inhibitory activity of withanolides involves targeting of the host cell surface receptor ACE2: insights from computational and biochemical assays, J Biomol Struct Dyn, (2021) 1-14. 
[47] R. Rodriguez-Puertas, ACE2 activators for the treatment of COVID 19 patients, J Med Virol, 92 (2020) 1701-1702.

[48] S. Najafi, E. Rajaei, R. Moallemian, F. Nokhostin, The potential similarities of COVID-19 and autoimmune disease pathogenesis and therapeutic options: new insights approach, Clin Rheumatol, 39 (2020) 3223-3235.

[49] Y. Chang, W. Wei, Angiotensin II in inflammation, immunity and rheumatoid arthritis, Clin Exp Immunol, 179 (2015) 137-145.

[50] M.C.S. Wong, S. Wong, J. Huang, B. Yan, Relating angiotensin-converting enzyme inhibitors or angiotensin receptor blockers with incidence or mortality of COVID-19, ESC Heart Fail, 7 (2020) 3119-3123.

[51] U. Mirastschijski, R. Dembinski, K. Maedler, Lung Surfactant for Pulmonary Barrier Restoration in Patients With COVID-19 Pneumonia, Front Med (Lausanne), 7 (2020) 254.

[52] S. Alivernini, L. MacDonald, A. Elmesmari, S. Finlay, B. Tolusso, M.R. Gigante, L. Petricca, C. Di Mario, L. Bui, S. Perniola, M. Attar, M. Gessi, A.L. Fedele, S. Chilaka, D. Somma, S.N. Sansom, A. Filer, C. McSharry, N.L. Millar, K. Kirschner, A. Nerviani, M.J. Lewis, C. Pitzalis, A.R. Clark, G. Ferraccioli, I. Udalova, C.D. Buckley, E. Gremese, I.B. Mclnnes, T.D. Otto, M. Kurowska-Stolarska, Distinct synovial tissue macrophage subsets regulate inflammation and remission in rheumatoid arthritis, Nat Med, 26 (2020) 1295-1306.

[53] L. MacDonald, S. Alivernini, B. Tolusso, A. Elmesmari, D. Somma, S. Perniola, A. Paglionico, L. Petricca, S.L. Bosello, A. Carfi, M. Sali, E. Stigliano, A. Cingolani, R. Murri, V. Arena, M. Fantoni, M. Antonelli, F. Landi, F. Franceschi, M. Sanguinetti, I.B. McInnes, C. McSharry, A. Gasbarrini, T.D. Otto, M. Kurowska-Stolarska, E. Gremese, COVID-19 and RA share SPP1 myeloid pathway that drives PD-L1pos neutrophils and CD14pos monocytes, JCI Insight, (2021). 
[54] M. Dougados, M. Soubrier, A. Antunez, P. Balint, A. Balsa, M.H. Buch, G. Casado, J. Detert, B. El-Zorkany, P. Emery, N. Hajjaj-Hassouni, M. Harigai, S.F. Luo, R. Kurucz, G. Maciel, E.M. Mola, C.M. Montecucco, I. Mclnnes, H. Radner, J.S. Smolen, Y.W. Song, H.E. Vonkeman, K. Winthrop, J. Kay, Prevalence of comorbidities in rheumatoid arthritis and evaluation of their monitoring: results of an international, cross-sectional study (COMORA), Ann Rheum Dis, 73 (2014) 62-68.

[55] T.R. Mikuls, S.R. Johnson, L. Fraenkel, R.J. Arasaratnam, L.R. Baden, B.L. Bermas, W. Chatham, S. Cohen, K. Costenbader, E.M. Gravallese, A.C. Kalil, M.E. Weinblatt, K. Winthrop, A.S. Mudano, A. Turner, K.G. Saag, American College of Rheumatology Guidance for the Management of Rheumatic Disease in Adult Patients During the COVID-19 Pandemic: Version 1, Arthritis Rheumatol, 72 (2020) 1241-1251.

[56] R.B. Landewe, P.M. Machado, F. Kroon, H.W. Bijlsma, G.R. Burmester, L. Carmona, B. Combe, M. Galli, L. Gossec, A. Iagnocco, J.D. Isaacs, X. Mariette, I. McInnes, U. Mueller-Ladner, P. Openshaw, J.S. Smolen, T.A. Stamm, D. Wiek, H. Schulze-Koops, EULAR provisional recommendations for the management of rheumatic and musculoskeletal diseases in the context of SARS-CoV-2, Ann Rheum Dis, 79 (2020) 851-858.

[57] C.D. Russell, J.E. Millar, J.K. Baillie, Clinical evidence does not support corticosteroid treatment for 2019-nCoV lung injury, Lancet, 395 (2020) 473-475.

[58] A. Strangfeld, M. Schafer, M.A. Gianfrancesco, S. Lawson-Tovey, J.W. Liew, L. Ljung, E.F. Mateus, C. Richez, M.J. Santos, G. Schmajuk, C.A. Scire, E. Sirotich, J.A. Sparks, P. Sufka, T. Thomas, L. Trupin, Z.S. Wallace, S. Al-Adely, J. Bachiller-Corral, S. Bhana, P. Cacoub, L. Carmona, R. Costello, W. Costello, L. Gossec, R. Grainger, E. Hachulla, R. Hasseli, J.S. Hausmann, K.L. Hyrich, Z. Izadi, L. Jacobsohn, P. Katz, L. Kearsley-Fleet, P.C. Robinson, J. Yazdany, P.M. Machado, C.-G.R. Alliance, Factors associated with COVID-19-related death in people with rheumatic diseases: results from the COVID-19 Global Rheumatology Alliance physician-reported registry, Ann Rheum Dis, 80 (2021) 930-942. 
[59] K.L. Hyrich, M. Gianfrancesco, P.M. Machado, J. Yazdany, P.C. Robinson, Rheumatic disease activity, glucocorticoid use and COVID-19. Response to: 'Comment on 'Characteristics associated with hospitalisation for COVID-19 in people with rheumatic disease: data from the COVID-19 Global Rheumatology Alliance physicianreported registry' by Gianfrancesco et al. Disease activity, rather than glucocorticoid therapy, may be associated with COVID-19 severity in patients with rheumatic musculoskeletal diseases' by Giollo et al, Ann Rheum Dis, (2020).

[60] L.C. Abu Esba, R.A. Alqahtani, A. Thomas, N. Shamas, L. Alswaidan, G. Mardawi, Ibuprofen and NSAID Use in COVID-19 Infected Patients Is Not Associated with Worse Outcomes: A Prospective Cohort Study, Infect Dis Ther, 10 (2021) 253-268.

[61] J.S. Chen, M.M. Alfajaro, R.D. Chow, J. Wei, R.B. Filler, S.C. Eisenbarth, C.B. Wilen, Non-steroidal anti-inflammatory drugs dampen the cytokine and antibody response to SARS-CoV-2 infection, J Virol, (2021).

[62] W. Qiao, C. Wang, B. Chen, F. Zhang, Y. Liu, Q. Lu, H. Guo, C. Yan, H. Sun, G. $\mathrm{Hu}, \mathrm{X}$. Yin, Ibuprofen attenuates cardiac fibrosis in streptozotocin-induced diabetic rats, Cardiology, 131 (2015) 97-106.

[63] J.K. Dhanjal, V. Kumar, S. Garg, C. Subramani, S. Agarwal, J. Wang, H. Zhang, A. Kaul, R.S. Kalra, S.C. Kaul, S. Vrati, D. Sundar, R. Wadhwa, Molecular mechanism of anti-SARS-CoV2 activity of Ashwagandha-derived withanolides, Int $\mathrm{J}$ Biol Macromol, 184 (2021) 297-312.

[64] J. Micallef, T. Soeiro, A.P. Jonville-Bera, T. French Society of Pharmacology, Nonsteroidal anti-inflammatory drugs, pharmacology, and COVID-19 infection, Therapie, 75 (2020) 355-362.

[65] J.T. Reese, B. Coleman, L. Chan, H. Blau, T.J. Callahan, L. Cappelletti, T. Fontana, K.R. Bradwell, N.L. Harris, E. Casiraghi, G. Valentini, G. Karlebach, R. Deer, J.A. McMurry, M.A. Haendel, C.G. Chute, E. Pfaff, R. Moffitt, H. Spratt, J. Singh, C.J. 
Mungall, A.E. Williams, P.N. Robinson, Cyclooxygenase inhibitor use is associated with increased COVID-19 severity, medRxiv, (2021).

[66] J. Fantini, C. Di Scala, H. Chahinian, N. Yahi, Structural and molecular modelling studies reveal a new mechanism of action of chloroquine and hydroxychloroquine against SARS-CoV-2 infection, Int J Antimicrob Agents, 55 (2020) 105960.

[67] C.T. Rentsch, N.J. DeVito, B. MacKenna, C.E. Morton, K. Bhaskaran, J.P. Brown, A. Schultze, W.J. Hulme, R. Croker, A.J. Walker, E.J. Williamson, C. Bates, S. Bacon, A. Mehrkar, H.J. Curtis, D. Evans, K. Wing, P. Inglesby, R. Mathur, H. Drysdale, A.Y.S. Wong, H.I. McDonald, J. Cockburn, H. Forbes, J. Parry, F. Hester, S. Harper, L. Smeeth, I.J. Douglas, W.G. Dixon, S.J.W. Evans, L. Tomlinson, B. Goldacre, Effect of pre-exposure use of hydroxychloroquine on COVID-19 mortality: a population-based cohort study in patients with rheumatoid arthritis or systemic lupus erythematosus using the OpenSAFELY platform, Lancet Rheumatol, 3 (2021) e19-e27.

[68] E.G. Favalli, F. Ingegnoli, R. Cimaz, R. Caporali, What is the true incidence of COVID-19 in patients with rheumatic diseases?, Ann Rheum Dis, 80 (2021) e18.

[69] B. Rochwerg, R.A. Siemieniuk, T. Agoritsas, F. Lamontagne, L. Askie, L. Lytvyn, A. Agarwal, Y.S. Leo, H. Macdonald, L. Zeng, W. Amin, E. Burhan, F.J. Bausch, C.S. Calfee, M. Cecconi, D. Chanda, B. Du, H. Geduld, P. Gee, N. Harley, M. Hashimi, B. Hunt, S.K. Kabra, S. Kanda, L. Kawano-Dourado, Y.J. Kim, N. Kissoon, A. Kwizera, I. Mahaka, H. Manai, G. Mino, E. Nsutebu, N. Pshenichnaya, N. Qadir, S. Sabzwari, R. Sarin, M. Shankar-Hari, M. Sharland, Y. Shen, S.S. Ranganathan, J.P. Souza, M. Stegemann, A. De Sutter, S. Ugarte, S. Venkatapuram, V.Q. Dat, D. Vuyiseka, A. Wijewickrama, B. Maguire, D. Zeraatkar, J.J. Bartoszko, L. Ge, R. BrignardelloPetersen, A. Owen, G. Guyatt, J. Diaz, M. Jacobs, P.O. Vandvik, A living WHO guideline on drugs for covid-19, BMJ, 370 (2020) m3379.

[70] P.C. Robinson, D.F.L. Liew, J.W. Liew, C. Monaco, D. Richards, S. Shivakumar, H.L. Tanner, M. Feldmann, The Potential for Repurposing Anti-TNF as a Therapy for the Treatment of COVID-19, Med (N Y), 1 (2020) 90-102. 
[71] I.O. Rosas, N. Brau, M. Waters, R.C. Go, B.D. Hunter, S. Bhagani, D. Skiest, M.S. Aziz, N. Cooper, I.S. Douglas, S. Savic, T. Youngstein, L. Del Sorbo, A. Cubillo Gracian, D.J. De La Zerda, A. Ustianowski, M. Bao, S. Dimonaco, E. Graham, B. Matharu, H. Spotswood, L. Tsai, A. Malhotra, Tocilizumab in Hospitalized Patients with Severe Covid-19 Pneumonia, N Engl J Med, 384 (2021) 1503-1516.

[72] C.A. Brito, J.G. Paiva, F.N. Pimentel, R.S. Guimaraes, M.R. Moreira, COVID-19 in patients with rheumatological diseases treated with anti-TNF, Ann Rheum Dis, (2020).

[73] E.G. Favalli, O. De Lucia, M. Biggioggero, N. Del Papa, R. Caporali, Role of antimalarials in COVID-19: observational data from a cohort of rheumatic patients, Ann Rheum Dis, (2020).

[74] A. Sepriano, A. Kerschbaumer, J.S. Smolen, D. van der Heijde, M. Dougados, R. van Vollenhoven, I.B. Mclnnes, J.W. Bijlsma, G.R. Burmester, M. de Wit, L. Falzon, R. Landewe, Safety of synthetic and biological DMARDs: a systematic literature review informing the 2019 update of the EULAR recommendations for the management of rheumatoid arthritis, Ann Rheum Dis, 79 (2020) 760-770.

[75] S. Monti, S. Balduzzi, P. Delvino, E. Bellis, V.S. Quadrelli, C. Montecucco, Clinical course of COVID-19 in a series of patients with chronic arthritis treated with immunosuppressive targeted therapies, Ann Rheum Dis, 79 (2020) 667-668.

[76] G.E. Fitzgerald, S. Maguire, N. Haroon, COVID-19: What Do Rheumatologists Need to Know?, Curr Rheumatol Rep, 23 (2021) 5.

[77] L. Gupta, D.P. Misra, V. Agarwal, S. Balan, V. Agarwal, Management of rheumatic diseases in the time of covid-19 pandemic: perspectives of rheumatology practitioners from India, Ann Rheum Dis, 80 (2021) e1.

[78] L. Costa, M. Tasso, N. Scotti, E. Mostacciuolo, N. Girolimetto, F. Foglia, A. Del Puente, R. Scarpa, F. Caso, Telerheumatology in COVID-19 era: a study from a psoriatic arthritis cohort, Ann Rheum Dis, (2020). 
[79] J. Mistry, M. Sharif, A. Prideaux, C. Smith, M. Sumbwanyambe, M. Sibley, L. Carpenter, M. Sweeney, P. Kiely, Use of rheumatoid arthritis impact of disease (RAID) in routine care; identification of DAS28 remission and unmet patient-reported outcomes, Rheumatol Adv Pract, 4 (2020) rkaa013.

[80] L.R. Knudsen, A. de Thurah, K. Lomborg, Experiences With Telehealth Followup in Patients With Rheumatoid Arthritis: A Qualitative Interview Study, Arthritis Care Res (Hoboken), 70 (2018) 1366-1372.

[81] W.H.O.R.E.A.f.C.-T.W. Group, J.A.C. Sterne, S. Murthy, J.V. Diaz, A.S. Slutsky, J. Villar, D.C. Angus, D. Annane, L.C.P. Azevedo, O. Berwanger, A.B. Cavalcanti, P.F. Dequin, B. Du, J. Emberson, D. Fisher, B. Giraudeau, A.C. Gordon, A. Granholm, C. Green, R. Haynes, N. Heming, J.P.T. Higgins, P. Horby, P. Juni, M.J. Landray, A. Le Gouge, M. Leclerc, W.S. Lim, F.R. Machado, C. McArthur, F. Meziani, M.H. Moller, A. Perner, M.W. Petersen, J. Savovic, B. Tomazini, V.C. Veiga, S. Webb, J.C. Marshall, Association Between Administration of Systemic Corticosteroids and Mortality Among Critically III Patients With COVID-19: A Meta-analysis, JAMA, 324 (2020) 1330-1341.

[82] K. Ranjbar, M. Moghadami, A. Mirahmadizadeh, M.J. Fallahi, V. Khaloo, R. Shahriarirad, A. Erfani, Z. Khodamoradi, M.H. Gholampoor Saadi, Methylprednisolone or dexamethasone, which one is superior corticosteroid in the treatment of hospitalized COVID-19 patients: a triple-blinded randomized controlled trial, BMC Infect Dis, 21 (2021) 337.

[83] M. Gianfrancesco, K.L. Hyrich, S. Al-Adely, L. Carmona, M.I. Danila, L. Gossec, Z. Izadi, L. Jacobsohn, P. Katz, S. Lawson-Tovey, E.F. Mateus, S. Rush, G. Schmajuk, J. Simard, A. Strangfeld, L. Trupin, K.D. Wysham, S. Bhana, W. Costello, R. Grainger, J.S. Hausmann, J.W. Liew, E. Sirotich, P. Sufka, Z.S. Wallace, J. Yazdany, P.M. Machado, P.C. Robinson, C.-G.R. Alliance, Characteristics associated with hospitalisation for COVID-19 in people with rheumatic disease: data from the COVID-19 Global Rheumatology Alliance physician-reported registry, Ann Rheum Dis, 79 (2020) 859-866. 
[84] M.S. Khuroo, Chloroquine and hydroxychloroquine in coronavirus disease 2019 (COVID-19). Facts, fiction and the hype: a critical appraisal, Int J Antimicrob Agents, 56 (2020) 106101.

[85] L. Jankelson, G. Karam, M.L. Becker, L.A. Chinitz, M.C. Tsai, QT prolongation, torsades de pointes, and sudden death with short courses of chloroquine or hydroxychloroquine as used in COVID-19: A systematic review, Heart Rhythm, 17 (2020) 1472-1479.

[86] N.J. White, J.A. Watson, R.M. Hoglund, X.H.S. Chan, P.Y. Cheah, J. Tarning, COVID-19 prevention and treatment: A critical analysis of chloroquine and hydroxychloroquine clinical pharmacology, PLoS Med, 17 (2020) e1003252.

[87] J. Liu, R. Cao, M. Xu, X. Wang, H. Zhang, H. Hu, Y. Li, Z. Hu, W. Zhong, M. Wang, Hydroxychloroquine, a less toxic derivative of chloroquine, is effective in inhibiting SARS-CoV-2 infection in vitro, Cell Discov, 6 (2020) 16.

[88] F. Atzeni, I.F. Masala, J. Rodriguez-Carrio, R. Rios-Garces, E. Gerratana, L. La Corte, M. Giallanza, V. Nucera, A. Riva, G. Espinosa, R. Cervera, The Rheumatology Drugs for COVID-19 Management: Which and When?, J Clin Med, 10 (2021).

[89] S.K. Mahil, N. Dand, K.J. Mason, Z.Z.N. Yiu, T. Tsakok, F. Meynell, B. Coker, H. McAteer, L. Moorhead, T. Mackenzie, M.T. Rossi, R. Rivera, E. Mahe, A. Carugno, M. Magnano, G. Rech, E.A. Balogh, S.R. Feldman, C. De La Cruz, S.E. Choon, L. Naldi, J. Lambert, P. Spuls, D. Jullien, H. Bachelez, D.E. McMahon, E.E. Freeman, P. Gisondi, L. Puig, R.B. Warren, P. Di Meglio, S.M. Langan, F. Capon, C.E.M. Griffiths, J.N. Barker, C.H. Smith, g. PsoProtect study, Factors associated with adverse COVID-19 outcomes in patients with psoriasis-insights from a global registry-based study, J Allergy Clin Immunol, 147 (2021) 60-71.

[90] L. Landi, C. Ravaglia, E. Russo, P. Cataleta, M. Fusari, A. Boschi, D. Giannarelli, F. Facondini, I. Valentini, I. Panzini, L. Lazzari-Agli, P. Bassi, E. Marchionni, R. Romagnoli, R. De Giovanni, M. Assirelli, F. Baldazzi, F. Pieraccini, G. Rametta, L. Rossi, L. Santini, 
I. Valenti, F. Cappuzzo, Blockage of interleukin-1beta with canakinumab in patients with Covid-19, Sci Rep, 10 (2020) 21775.

[91] J. Geng, F. Wang, Z. Huang, X. Chen, Y. Wang, Perspectives on anti-IL-1 inhibitors as potential therapeutic interventions for severe COVID-19, Cytokine, 143 (2021) 155544.

[92] G.M. Casillo, A.A. Mansour, F. Raucci, A. Saviano, N. Mascolo, A.J. lqbal, F. Maione, Could IL-17 represent a new therapeutic target for the treatment and/or management of COVID-19-related respiratory syndrome?, Pharmacol Res, 156 (2020) 104791.

[93] X. Xu, M. Han, T. Li, W. Sun, D. Wang, B. Fu, Y. Zhou, X. Zheng, Y. Yang, X. Li, X. Zhang, A. Pan, H. Wei, Effective treatment of severe COVID-19 patients with tocilizumab, Proc Natl Acad Sci U S A, 117 (2020) 10970-10975.

[94] C. Calabrese, P. Rajendram, G.L. Sacha, L. Calabrese, Practical aspects of targeting IL-6 in COVID-19 disease, Cleve Clin J Med, (2020).

[95] L. Castelnovo, A. Tamburello, A. Lurati, E. Zaccara, M.G. Marrazza, M. Olivetti, N. Mumoli, D. Mastroiacovo, D. Colombo, E. Ricchiuti, P. Vigano, F. Paola, A. Mazzone, Anti-IL6 treatment of serious COVID-19 disease: A monocentric retrospective experience, Medicine (Baltimore), 100 (2021) e23582.

[96] K.M. D'Silva, Z.S. Wallace, COVID-19 and Disease-Modifying Anti-rheumatic Drugs, Curr Rheumatol Rep, 23 (2021) 28.

[97] O. Pacha, M.A. Sallman, S.E. Evans, COVID-19: a case for inhibiting IL-17?, Nat Rev Immunol, 20 (2020) 345-346.

[98] F. Seif, H. Aazami, M. Khoshmirsafa, M. Kamali, M. Mohsenzadegan, M. Pornour, D. Mansouri, JAK Inhibition as a New Treatment Strategy for Patients with COVID-19, Int Arch Allergy Immunol, 181 (2020) 467-475. 


\section{Legends to the Figures:}

Figure 1. Immune-inflammatory activities in SARS-CoV-2 infection. Immune response against SARS-CoV-2 in normal (A) and dysfunctional (B) defense pathogenic mechanisms. Schematic diagram showing functions of different immune components in their designated signalings and impact of various pro-inflammatory mediators in normal (A) and cytokine storm (B) environments.

Figure 2. Immune-inflammatory activities in rheumatoid arthritis (RA). RA is characterized by dysfunctional adaptive immunity against 'self' antigens and dysregulated cytokine set-ups. APC led activation of Th2 and Th17 promote B cell differentiation and IL-17 release respectively. CD4+ $T$ cell functions to induce chronic autoimmune response of RA via antigenic activation of naive CD8+ T cells that triggers inflammation via massive production of pro-inflammatory mediators including TNF- $\alpha$, IL$1 \beta$, and IL-6. Th1 hyperactivation in RA triggers IFN- $\gamma$, IL-2, and TNF- $\alpha$ levels. Th17/IL17 axis function by eliciting L-1 $\beta$, IL-6, TNF- $\alpha$ levels, activation of microphage, neutrophils, B plasma cells. Herein, an enhanced IL-17 expression is shown to produce pro-inflammatory IL-6, IL-8, VEGF-A, and matrix metalloproteinases (MMP-1 and -3) in RA synovial fibroblasts.

Figure 3. Angiotensin-converting enzyme (ACE)-dependent pathway showing mechanistic similarity between SARS-CoV-2 infection and RA. ACE2 catalyzes the conversion of angiotensin II to angiotensin-1-7 and shares identical pathological signaling in both COVID-19 (ACE2 binding by SARS-CoV-2) and RA that involves function of pro-inflammatory cytokines in promoting inflammation, fibrosis, vasoconstriction, and apoptotic activities.

Figure 4. Macrophage-mediated pathway showing mechanistic similarity between SARS-CoV-2 infection and RA. Schematic diagram showing pro-inflammatory function of distinct macrophage subsets in the normal (uninfected) and SARS-CoV-2 infected alveolar tissue (upper) and synovial tissue of normal (healthy) and RA patients (lower). Identity of distinct participating macrophage subsets is showing at bottom. 


\section{Figure 1}

A Immune response against SARS-CoV-2 in defense mechanism

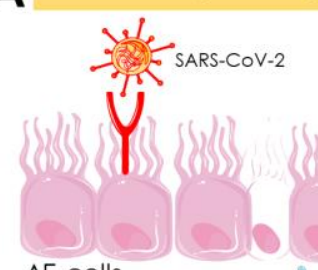

AE cells

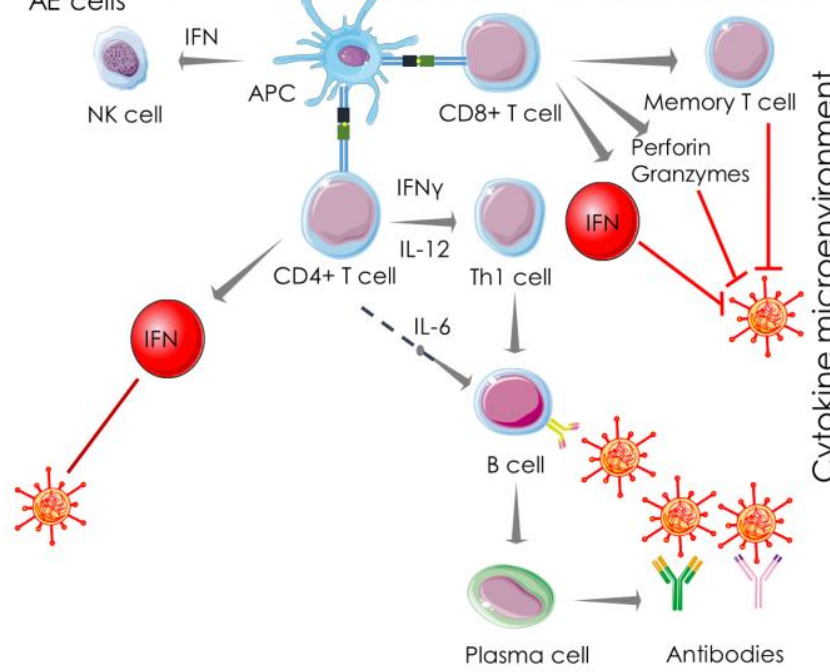

B Dysfunctional immunity + lymphopenia in pathogenic mechanism

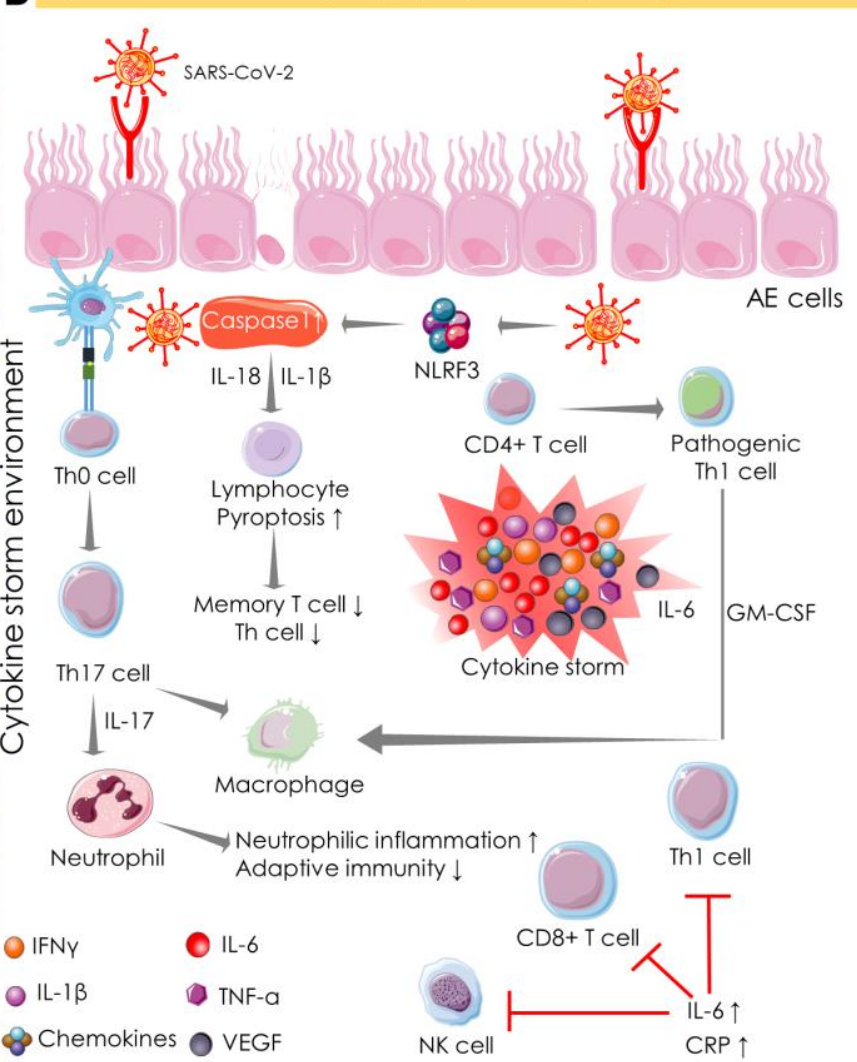


Figure 2

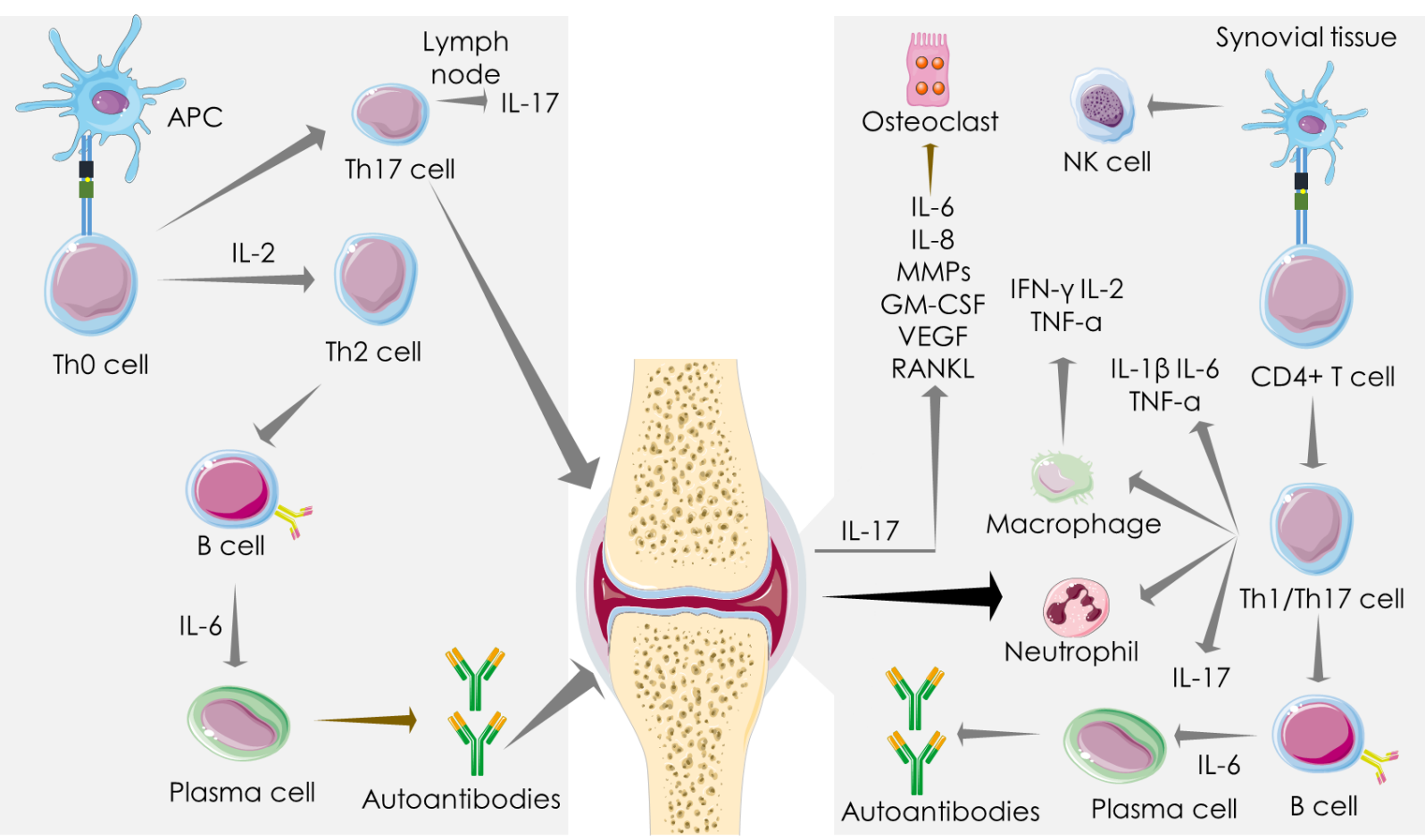


Figure 3

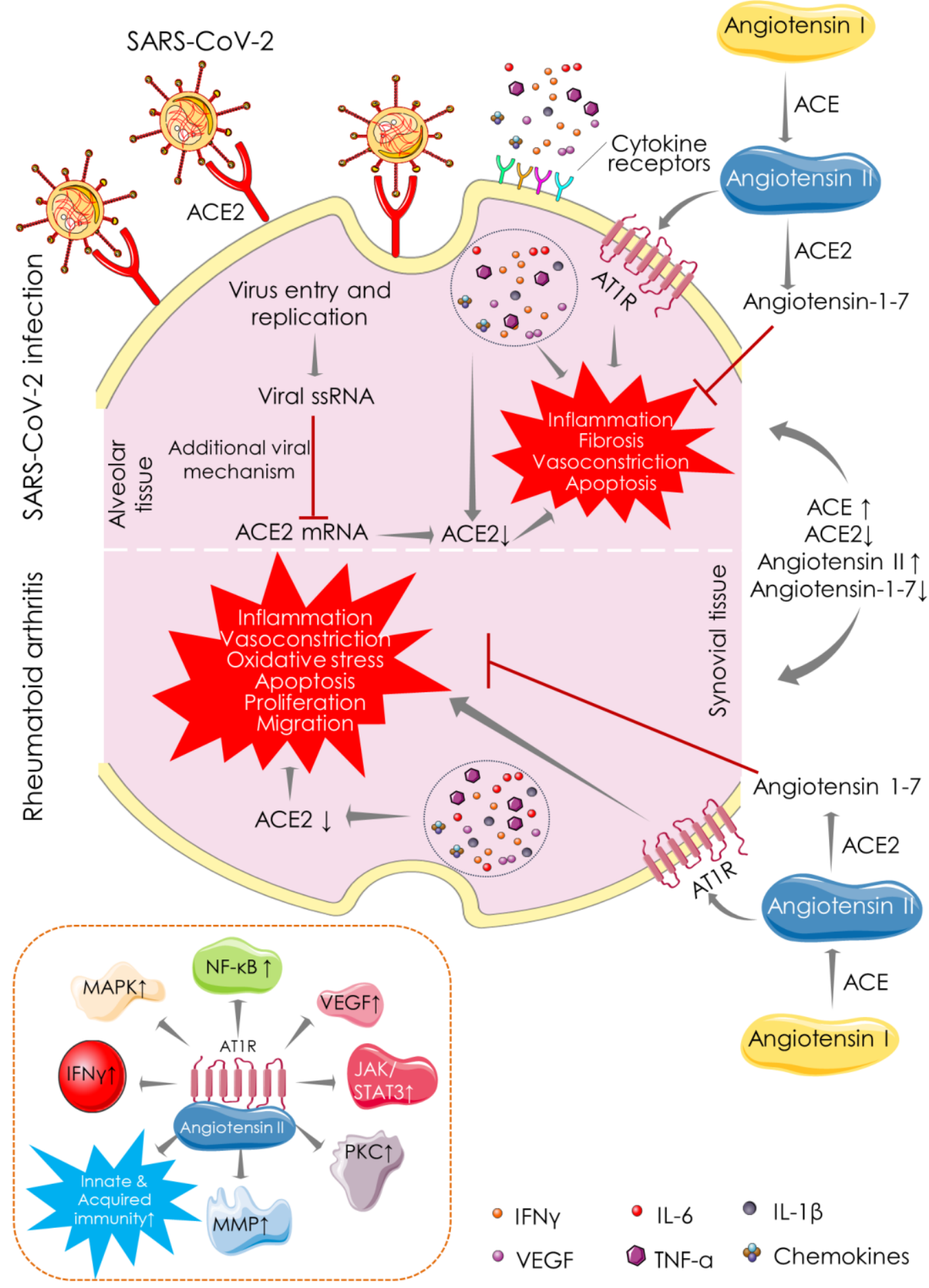


Figure 4

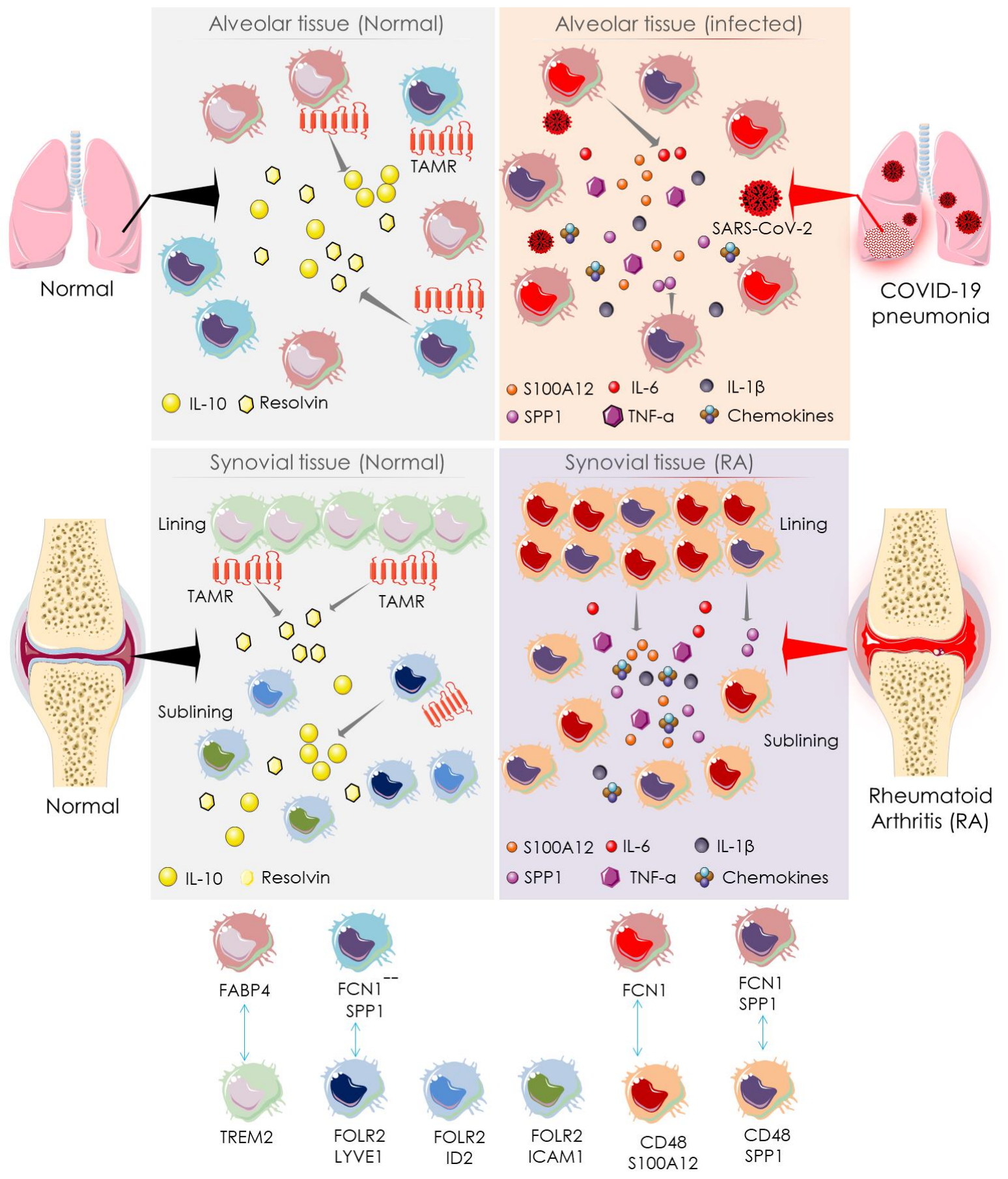


Table 1. Indications, contraindications and recommendations of the important anti-rheumatic drugs used in COVID-19 setting.

\begin{tabular}{|c|c|c|c|c|c|}
\hline Class of drugs & Drugs & Indications & Contraindications & $\begin{array}{l}\text { Recommendations for RA } \\
\text { patients acquiring COVID- } \\
19 \text { infection }\end{array}$ & References \\
\hline Glucocorticoids & $\begin{array}{l}\text { Dexamethasone, } \\
\text { Hydrocortisone, } \\
\text { Methylprednisolone. }\end{array}$ & $\begin{array}{l}\text { Immunosuppressive agents } \\
\text { and reduce inflammation } \\
\text { (during late phases of } \\
\text { infection), mortality, and } \\
\text { length of hospitalization. }\end{array}$ & $\begin{array}{l}\text { Increase the risk of acquiring } \\
\text { infection, moderate to high } \\
\text { dose can yield poor outcomes. }\end{array}$ & $\begin{array}{l}\text { Continue at lowest possible } \\
\text { dose; however, sudden } \\
\text { withdrawal is not } \\
\text { recommended. }\end{array}$ & $\begin{array}{l}{[23,58,68,} \\
81-83]\end{array}$ \\
\hline NSAIDs & $\begin{array}{l}\text { Naproxen, } \\
\text { Celecoxib, } \\
\text { Etoricoxib, } \\
\text { lbuprofen, } \\
\text { Ketoprofen, } \\
\text { Aspirin, Acetaminophen. }\end{array}$ & $\begin{array}{l}\text { Suppress inflammation and } \\
\text { reduce fever. }\end{array}$ & $\begin{array}{l}\text { Impair humoral immune } \\
\text { response, increase the risk of } \\
\text { bacterial infection; increase } \\
\text { severity and mortality (non- } \\
\text { selective COX inhibitors). }\end{array}$ & $\begin{array}{l}\text { Continue unless the patient } \\
\text { with severe systemic } \\
\text { manifestations. }\end{array}$ & {$[61,64,65]$} \\
\hline $\begin{array}{l}\text { csDMARDs } \\
\text { Antimalarials }\end{array}$ & $\begin{array}{l}\text { Hydroxychloroquine, } \\
\text { Chloroquine. }\end{array}$ & $\begin{array}{l}\text { Not clearly understood, } \\
\text { believed to exhibit antiviral } \\
\text { effect via preventing viral } \\
\text { entry, transport, and post- } \\
\text { invasion events. } \\
\text { Hydroxychloroquine is more } \\
\text { potent and less toxic }\end{array}$ & $\begin{array}{l}\text { Dangerous when overdosed, } \\
\text { cardiovascular side effect (QT } \\
\text { prolongation). Maculopathy, } \\
\text { retinal alteration, G6PD } \\
\text { Deficiency, and } \\
\text { Hypersensitivity are other } \\
\text { contraindications. Special } \\
\text { attention is required for } \\
\text { injections. }\end{array}$ & $\begin{array}{l}\text { Temporary suspension for } \\
\text { RA patients with suspected/ } \\
\text { confirmed SARS-CoV-2 } \\
\text { infection; patients with } \\
\text { chronic heart failure, and/or } \\
\text { patients receiving QT } \\
\text { prolonging agents, such as } \\
\text { azithromycin. }\end{array}$ & $\begin{array}{l}{[66,68,84-} \\
88]\end{array}$ \\
\hline Other csDMARDs & $\begin{array}{l}\text { Methotrexate, } \\
\text { Leflunomide, } \\
\text { Sulfasalazine. }\end{array}$ & $\begin{array}{l}\text { Immunosuppressive agents } \\
\text { and suppress inflammation. }\end{array}$ & $\begin{array}{l}\text { Increase the risk of poor } \\
\text { outcomes. Combination } \\
\text { therapy yields poor outputs } \\
\text { then monotherapy. }\end{array}$ & $\begin{array}{l}\text { Suspension for RA patients } \\
\text { with suspected/confirmed } \\
\text { SARS-CoV-2 infection }\end{array}$ & {$[58,68]$} \\
\hline $\begin{array}{l}\text { bDMARDs } \\
\text { Anti-TNF drugs }\end{array}$ & $\begin{array}{l}\text { Adalimumab, } \\
\text { Infliximab, Certolizumab } \\
\text { pegol, Etanercept, } \\
\text { Golimumab, } \\
\text { Secukinumab. } \\
\end{array}$ & $\begin{array}{l}\text { Suppress inflammation and } \\
\text { reduce GM-CSF, VEGF, } \\
\text { CRP, and blood coagulation. }\end{array}$ & $\begin{array}{l}\text { Increase the risk of acquiring } \\
\text { infection, hypersensitivity and } \\
\text { few cases of poor outcomes. }\end{array}$ & $\begin{array}{l}\text { Suspension for RA patients } \\
\text { with suspected/confirmed } \\
\text { SARS-CoV-2 infection. }\end{array}$ & $\begin{array}{l}{[28,68,70,} \\
88,89]\end{array}$ \\
\hline Anti-IL-1 drugs & $\begin{array}{l}\text { Anakinra, } \\
\text { Canakinumab, } \\
\text { Rilonacept. }\end{array}$ & $\begin{array}{l}\text { Suppress inflammation, } \\
\text { prevent overpowering of } \\
\text { innate immunity, improve } \\
\text { oxygen saturation, reduce } \\
\text { neutrophil counts and inhibit } \\
\text { Th17 cell induction. }\end{array}$ & $\begin{array}{l}\text { Increase the risk of acquiring } \\
\text { infection and hypersensitivity. }\end{array}$ & $\begin{array}{l}\text { Suspension for RA patients } \\
\text { with Suspected/confirmed } \\
\text { SARS-CoV-2 infection. }\end{array}$ & $\begin{array}{l}{[68,88,90-} \\
92]\end{array}$ \\
\hline
\end{tabular}




\begin{tabular}{|c|c|c|c|c|c|}
\hline Anti-IL-6 drugs & $\begin{array}{l}\text { Tocilizumab, } \\
\text { Sarilumab. }\end{array}$ & $\begin{array}{l}\text { Suppress inflammation, } \\
\text { prevent immune damage to } \\
\text { target cells, improve oxygen } \\
\text { saturation and reduce CRP, } \\
\text { neutrophil counts, and fever. }\end{array}$ & $\begin{array}{l}\text { Increase the risk of acquiring } \\
\text { infection. Hypersensitivity, } \\
\text { thrombocytopenia, leukopenia, } \\
\text { aminotransferase elevation } \\
\text { and gastrointestinal } \\
\text { perforations (rare) are other } \\
\text { contraindications. }\end{array}$ & $\begin{array}{l}\text { Initiation or continuation is } \\
\text { recommended even in } \\
\text { COVID-19-positive cases. }\end{array}$ & $\begin{array}{l}{[68,88,93-} \\
96]\end{array}$ \\
\hline Anti-IL-17 drugs & $\begin{array}{l}\text { Brodalumab, } \\
\text { Ixekizumab (LY2439821), } \\
\text { Secukinumab (AIN457). }\end{array}$ & $\begin{array}{l}\text { Suppress inflammation, } \\
\text { inhibit the production of IL-1, } \\
\text { IL-8, and IL-6, exhibit } \\
\text { immune-modulatory effect, } \\
\text { and reduce neutrophil } \\
\text { recruitment. }\end{array}$ & $\begin{array}{l}\text { Increase the risk of acquiring } \\
\text { infection. }\end{array}$ & $\begin{array}{l}\text { Suspension for RA patients } \\
\text { with suspected/confirmed } \\
\text { SARS-CoV-2 infection. }\end{array}$ & {$[68,89,97]$} \\
\hline Anti-IL-23 drugs & $\begin{array}{l}\text { Guselkumab, } \\
\text { Risankizumab, } \\
\text { Tildrakizumab, } \\
\text { Ustekinumab. }\end{array}$ & $\begin{array}{l}\text { Suppress inflammation, } \\
\text { inhibit IL12/IL-23p40 or IL- } \\
\text { 23p19, and inhibit Th17 cell } \\
\text { induction. }\end{array}$ & $\begin{array}{l}\text { Increase the risk of acquiring } \\
\text { infection and hypersensitivity. }\end{array}$ & $\begin{array}{l}\text { Suspension for RA patients } \\
\text { with suspected/confirmed } \\
\text { SARS-CoV-2 infection. }\end{array}$ & {$[68,89,92]$} \\
\hline $\begin{array}{l}\text { tsDMARDs } \\
\text { JAK inhibitors }\end{array}$ & $\begin{array}{l}\text { Baricitinib, } \\
\text { Ruxolitinib, } \\
\text { Tofacitinib, } \\
\text { Upadacitinib. }\end{array}$ & $\begin{array}{l}\text { Decrease virus infectivity, } \\
\text { inhibit type } 1 / / l \text { cytokine } \\
\text { receptors, reduce } \\
\text { inflammation and decrease } \\
\text { neutrophil counts. }\end{array}$ & $\begin{array}{l}\text { Impair IFN-mediated anti-viral } \\
\text { response, increase the risk of } \\
\text { secondary infection, venous } \\
\text { thromboembolism, and } \\
\text { hypersensitivity. }\end{array}$ & $\begin{array}{l}\text { Suspension for RA patients } \\
\text { with suspected/confirmed } \\
\text { SARS-CoV-2 infection }\end{array}$ & $\begin{array}{l}{[68,73,74,} \\
88,98]\end{array}$ \\
\hline
\end{tabular}

NSAIDs- Non-steroidal anti-inflammatory drugs; csDMARDs- Conventional synthetic disease-modifying antirheumatic drugs; bDMARDs- Biological diseasemodifying antirheumatic drugs; tsDMARDs- Targeted synthetic disease-modifying antirheumatic drugs. 